\title{
Observations of extreme wave runup events on the U.S. Pacific Northwest coast
}

\author{
Chuan $\mathrm{Li}^{1}$, H. Tuba Özkan-Haller ${ }^{1,2}$, Gabriel García-Medina ${ }^{3}$, Robert A. Holman ${ }^{2}$, Peter Ruggiero ${ }^{2}$, \\ Treena M. Jensen ${ }^{4}$, David B. Elson ${ }^{4}$, and William R. Schneider ${ }^{4}$ \\ ${ }^{1}$ School of Civil and Environmental Engineering, Oregon State University, Corvallis, OR, USA \\ ${ }^{2}$ College of Earth, Ocean, and Atmospheric Sciences, Oregon State University, Corvallis, OR, USA \\ ${ }^{3}$ Marine Sciences Laboratory, Pacific Northwest National Laboratory, Seattle, WA, USA \\ ${ }^{4}$ National Weather Service, National Ocean and Atmospheric Administration, Portland, OR, USA
}

Correspondence: Chuan Li (chuan.li@oregonstate.edu)

\begin{abstract}
Extreme, tsunami-like wave runup events in the absence of earthquakes or landslides have been attributed to trapped waves over shallow bathymetry and long waves created by atmospheric disturbances. These runup events are associated with inland excursions of hundreds of meters and periods of minutes. While the theory of radiation stress implies that nearshore energy transfer from the carrier waves to the infragravity waves can also lead to very large runup, there have not been observations of runup events induced by this process with magnitudes and periods comparable to the other two mechanisms. This work presents observations of several runup events in the U.S. Pacific Northwest that are comparable to extreme runup events related to trapped waves and atmospheric disturbances. It also discusses possible generation mechanisms and shows that energy transfer from incident waves to bound infragravity waves is a plausible generation mechanism. In addition, a method to predict and forecast extreme runup events with similar characteristics is presented.
\end{abstract}

\section{Introduction}

Wave runup (hereafter referred to simply as runup) is defined as the maximum excursion of water level at the shoreline. Runup is an important process that contributes to coastal flooding and beach and dune erosion and accretion. Very large runup events can be dangerous to beach goers in certain regions of the world, such as the the Pacific Northwest (PNW) coast of the United States. This region includes the coasts of Washington, Oregon, and Northern California. Records in this region show that large runup events are the leading cause of deaths by drowning, including incidents when the runup moves logs that then contribute to the fatality (D. Elson, personal communication, 2016). Since 2005, there have been about two drowning deaths due to large runup events each year in this region (Garcia-Medina et al., 2018).

There have been numerous studies focused on better understanding and prediction of runup using laboratory (e.g. Hunt, 1959; Battjes, 1974; Hedges and Mase, 2004; Hughes, 2004; van der Meer and Stam, 1992; Mase, 1989; Blenkinsopp et 
al., 2016), field (e.g. Holman, 1986; Ruggiero et al., 2001; Baldock and Holmes, 1997; Stockdon et al., 2006; Fiedler et al., 2015), and numerical methods (e.g. Fiedler et al., 2018; Garcia-Medina et al., 2017; Montoya and Lynett, 2018). Many of these studies examine the relationship between runup and beach slope and wave conditions - usually wave height and wave length. For example, Stockdon et al. (2006) produced a relationship between the $2 \%$ exceedance value of runup maxima and the beach slope, wave height, and wave length using data from several natural beaches. Some studies examine the ability of numerical models to simulate runup. For example, Fiedler et al. (2018) show that one-dimensional non-hydrostatic models can predict runup with reasonable accuracy.

Some studies have focused on infrequent runup events with very large magnitudes that are not related to earthquakes or landslides. Aside from being potentially dangerous to beach goers, these runup events are important because they erode and deposit sediments at locations not usually affected by runup (e.g. Dewey and Ryan, 2017) and can potentially damage properties and structures (e.g. Roeber and Bricker, 2015). Observations of such runup events have been so far been attributed to two mechanisms: trapped waves over shallow bathymetry (e.g. Sheremet et al., 2014; Roeber and Bricker, 2015; Montoya and Lynett, 2018) and long waves created by atmospheric disturbances - also known as meteotsunamis (e.g. Monserrat et al., 2006; Olabarrieta et al., 2017). It has also been implied by the theory of radiation stress, that energy transfer from carrier waves to bound infragravity waves can result in infragravity waves of very large heights (e.g. Longuet-Higgins and Stewart, 1962; Battjes et al., 2004), and can potentially lead to very large runup. However, no observed runup with magnitude comparable to those due to the other two mechanisms have been attributed to the energy transfer mechanism.

The primary aim of this work is to show for the first time, through a set of observations, that energy transfer from carrier waves to bound waves is a plausible generation mechanism of runup with magnitudes and periods comparable to those from trapped waves over shallow bathymetry and those from meteotsunamis. The majority of this study is based on a set of observations on the PNW coast on January 16, 2016. On this day, at least five different large runup events - some with more than a hundred meters of horizontal excursion, and all at different locations - were captured on video by beach goers. In addition, at least two runup related injury events were documented. The video footage and injuries took place along a $1000 \mathrm{~km}$ stretch of coastline within 5 hours of each other. Measurements from a number of instruments at various locations are analyzed. Possible generation mechanisms and comparisons to other similar observations are discussed. Lastly, a method to predict and forecast similar events is presented.

\section{Study site}

The wave climate of the PNW coast (Figure 1) is characterized by large wave heights and long wave periods, especially in the winter. For example, from 2008 to 2018 the median and 95 percentile of significant wave height for the summer month of August are $1.4 \mathrm{~m}$ and $2.5 \mathrm{~m}$. For the winter month of January, they are $2.8 \mathrm{~m}$ and $5.3 \mathrm{~m}$. For peak wave period they are $8.3 \mathrm{~s}$ and $14.8 \mathrm{~s}$ for August and $12.9 \mathrm{~s}$ and $17.4 \mathrm{~s}$ for January (NOAA, 2020a). The reason for this is due to the large fetch and strong winds in the north Pacific storm systems, which are especially effective during the winter as the storm systems move across the ocean basin and achieve landfall (Tillotson and Komar, 1997). 


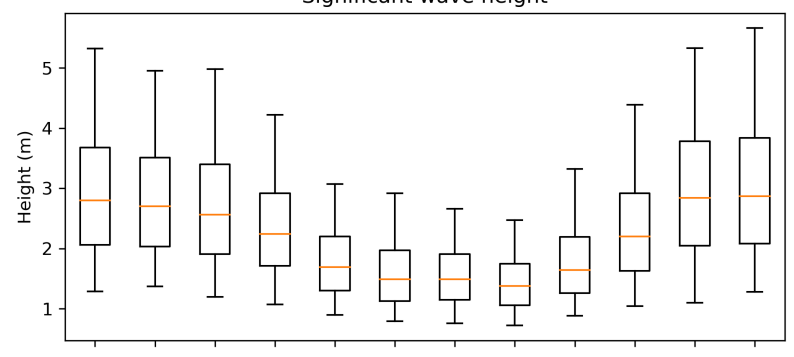

Dominant wave period

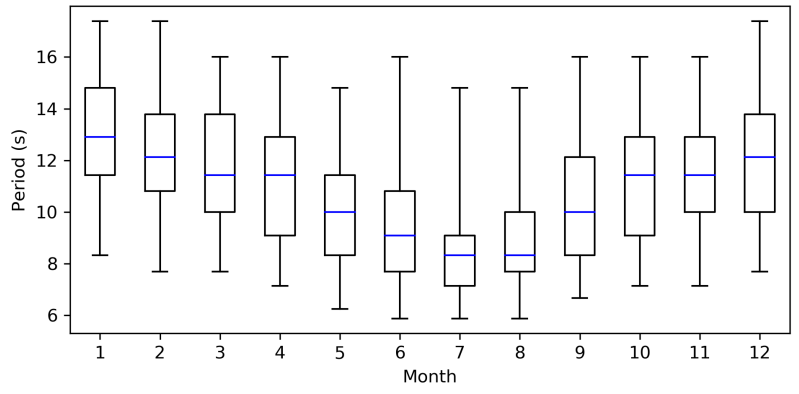

Figure 1. Significant wave height and peak wave period of the Pacific Northwest coasts (Washington, Oregon, and Northern California) from 2008-2018. Boxes indicate 25, 50, and 75 percentiles whereas whiskers indicate 5 and 95 percentiles (NOAA, 2020a).

The PNW coast is also known for having low-sloping beaches. For example, upper shoreface slope from the central Oregon coast to the central Washington coast ranges between 0.005 to 0.02 (Di Leonardo and Ruggiero, 2015). There have been several studies on runup in this region. For example, Ruggiero et al. (2004) analyzed 1.5-hour water level time-series along several cross-shore transects on Agate Beach (located on central Oregon coast). During this period the offshore wave height and wave period were $2.3 \mathrm{~m}$ and $13 \mathrm{~s}$ respectively. Runup was found to vary alongshore by a factor of 2 and was found to be proportional to foreshore beach slope. In addition, approximately $96 \%$ of the runup energy was contained in low frequencies (less than 0.05 Hz). Fiedler et al. (2015) analyzed runup on a single transect over a 44-day period, also on Agate Beach. During this time the wave height ranged from $0.5 \mathrm{~m}$ to $7 \mathrm{~m}$. The top $2 \%$ of runup were found to be approximately linearly proportional to the square root of wave height and wave length. In addition, the amplification of low frequency motion was found to decrease dramatically during storms. Holman and Bowen (1984) analyzed wave runup on several locations along the mid-Oregon coast and found that $99.9 \%$ of runup variance are attributed to periods of greater than $20 \mathrm{~s}$, and that $83 \%$ of runup variance are attributed to periods of greater than $50 \mathrm{~s}$.

\section{Background of observed large runup events}

Direct observations of unusually large runup events are scarce. A remarkably well documented case took place on January 16, 2016, when multiple unusually large runup events were observed along the coast of the PNW. There were multiple video 
https://doi.org/10.5194/nhess-2020-425

Preprint. Discussion started: 26 January 2021

(c) Author(s) 2021. CC BY 4.0 License.
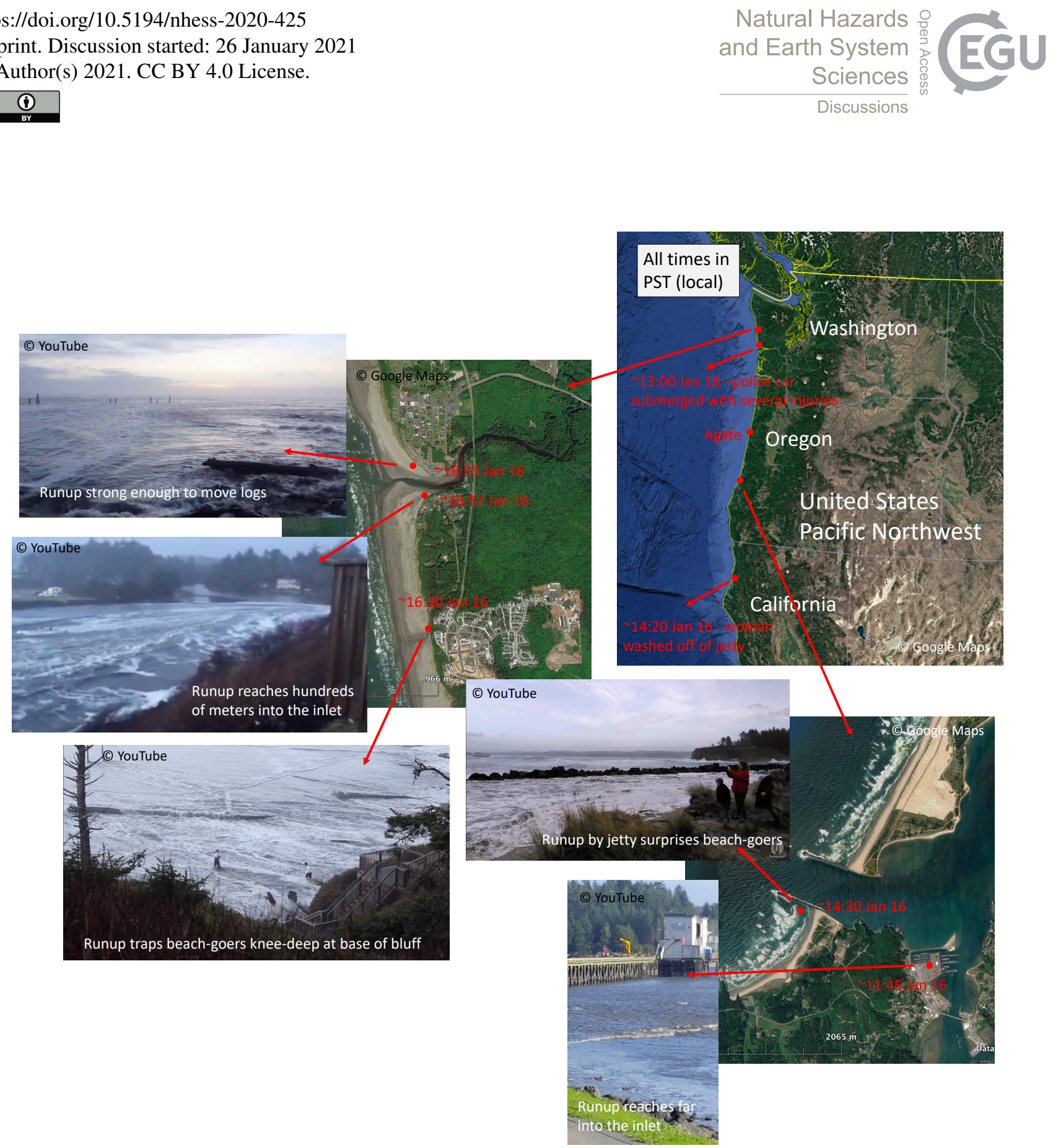

Figure 2. Location and approximate occurrence time of January 16, 2016 large wave runup events and stills from videos taken by bystanders. Photos are from YouTube (2020a,b,c,d,e), maps are from Google Maps.

recordings and injury reports within approximately 5 hours and along an approximately $1000 \mathrm{~km}$ stretch of coastline (Figure 70 2). The following is a list of known large runup events in chronological order (all times in PST, i.e. local time):

January 16 11:45, Charleston, Oregon: a video recording taken by a bystander shows a large drawdown well inside an inlet. This is followed by a succeeding large runup event at the same location approximately 3 minutes later (YouTube, 2020a). 
January 16 13:10, Ocean Shores, Washington ( $\sim 410 \mathrm{~km}$ north of Charleston): a report shows that around this time a police car was completely submerged by water as the police officer tried to drive away from a runup event (Jensen, 2016). Several people needed to be rescued and several were injured as they were running away from the high water event.

January 16, 14:20, Humboldt Bay, California ( $290 \mathrm{~km}$ south of Charleston): a woman was washed off of a jetty and was later recovered (Jensen, 2016).

January 16 14:30, Charleston, Oregon: an extreme runup event progressed hundreds of meters inland and surprised many beach goers, including the video taker (YouTube, 2020b).

January 16 16:30, Seabrook, Washington ( $\sim 30 \mathrm{~km}$ north of Charleston): a very large runup strong enough to move logs traped several beach goers knee-deep in water in front of bluffs (YouTube, 2020c).

January 16 16:52, Pacific Beach, Washington ( 430 km north of Charleston): a large runup event progressed hundreds of meters inland and proceeded to travel up a small coastal stream (YouTube, 2020d).

January 16 16:55, Pacific Beach, Washington: a large runup mobilized several logs and pushed them against a stretch of riprap. A large reflected wave is also seen traveling offshore (YouTube, 2020e).

Large water-level fluctuations were observed along the same 1000-km stretch of coast during the same time by tide gages with both 6-minute and 1-minute recording intervals. The amplitudes of these water level fluctuations reached as high as about $0.5 \mathrm{~m}$. Further detail is shown in the results sections. Wave runups of similar scale in magnitude have been observed at other times in this region, though typically not with as many video recordings from bystanders across the stretch of coastline as was on January 16, 2016.

\section{Methods}

Observations from three sources are presented in this study to provide various data across a range of locations and over different water depths. Table 1 lists the data types, measurement frequency, water depth, and distance from shore for each site. Figure 3 shows the locations of observation sites. Water level, wind speed, and atmospheric pressure from six NOAA CO-OPS stations are used. These gages are located at the coast and span approximately $800 \mathrm{~km}$ of coastline between Northern California and Northern Washington. In addition, wave height, wave period, and wave energy density spectra from five NDBC buoys are used. These buoys span a similar range as the NOAA CO-OPS tide gages but are located further offshore on the continental shelf. Also used are water column height from four bottom sensors from the Deep-ocean Assessment and Report of Tsunamis (DART) system. These sensors span approximately $1200 \mathrm{~km}$ from north to south and are much further offshore than the NDBC buoys and are in the deep ocean.

\subsection{Tide gages}

The NOAA CO-OPS tide gages (NOAA, 2020b) are located at the coast. Five out of the six tide gages used in this study are located inside estuaries (except for Crescent City which is in a harbor). Figure 4 shows satellite images around each sensor. Data used in this study at these locations include water level, atmospheric pressure, and wind speed. Water level is measured 


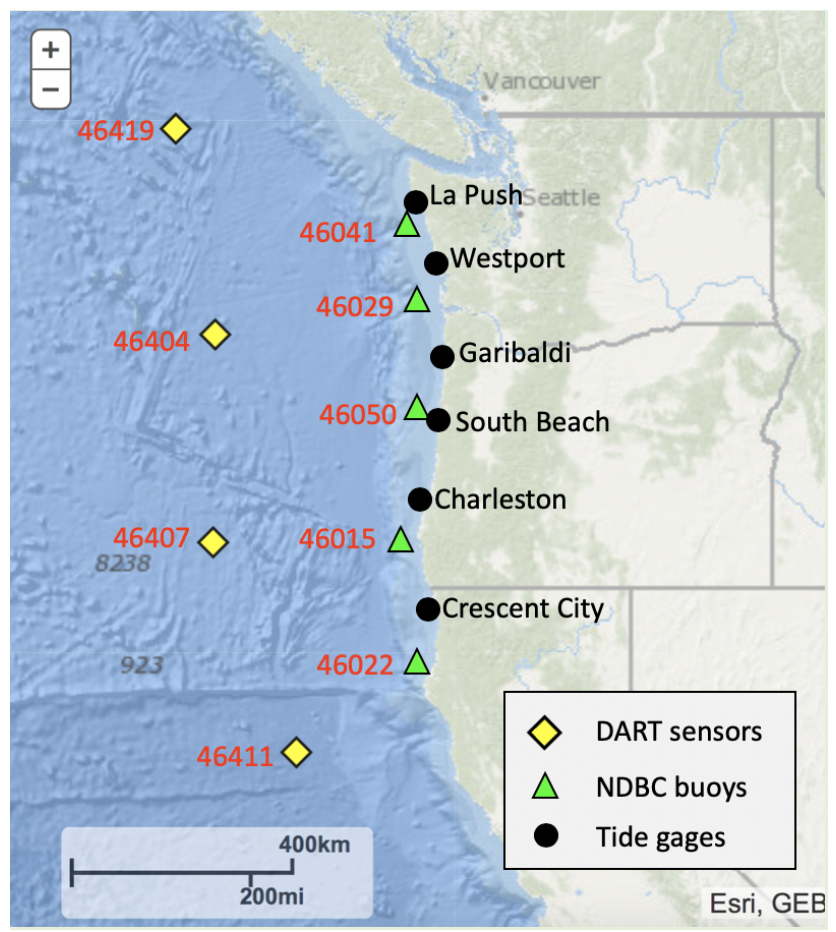

Figure 3. Locations of observation sites (map from NOAA, 2020a).

either from acoustic ranging (at Westport, Garibaldi, South Beach, and Charleston) or microwave radar sensors (at La Push and Crescent City) (NOAA, 2020b). Data is sampled at $1 \mathrm{~Hz}$ and averaged over 1 minute to produce 1-minute time series. Frequency analysis on the water level time series are performed via Fast Fourier Transform with 18 degrees of freedom over record lengths between 708 and 715 samples. Atmospheric pressure is measured from pressure sensors mounted between 7.7 $\mathrm{m}$ to $11 \mathrm{~m}$ above mean sea level (NOAA, 2020b). 21 six-second samples over 2 minutes are averaged and collected every 6 minutes. Wind speed is measured from anenometers mounted between $11 \mathrm{~m}$ and $30 \mathrm{~m}$ above sea level. 2-minute average of 1-Hz samples are collected every 6 minutes.

For the analysis sought in this work, it is important to determine the intensity of water level fluctuations at the tide gages. One method of representing such intensity is by generating an envelope of the time series. This is often done by using a Hilbert transform. When the time series has signals with high frequencies, however, the resulting Hilbert transform will also contain high frequency signals. In this case, it is necessary then to remove the high frequency signals by a low-pass filter. Another method is to compute the root-mean-square (RMS) of the time series over a specified window. The two methods yield similar results. The RMS method is chosen over the Hilbert transform method for its simpler implementation. 


\subsection{Buoys}

NDBC buoys (NOAA, 2020a) are moored buoys located $45-85 \mathrm{~km}$ offshore at water depths of 128-400 m. All stations used in this study are of the 3-meter discus type buoys. Data used at these locations include significant wave height and peak wave period - both recorded at 1-hour intervals. Also used at these locations are wave spectral density, also recorded at 1-hour intervals, across a frequency range of $0.02 \mathrm{~Hz}$ to $0.485 \mathrm{~Hz}$. Data acquisition starts at the 20th minute of each hour and continues for 20 minutes. During this time, buoy motions are measured and then transformed from the temporal to the spectral domain.

The energy density spectra derived from wave motions can be useful in characterizing the sea state. A useful parameter that can be computed from ocean wave spectra is the spectral moment:

$m_{n}=\int_{-\infty}^{\infty} f^{n} E(f) d f$

where $n$, typically an integer, denotes the $n$-th moment, $E(f)$ is the energy density, and $f$ is the frequency. In metric units, $E(f)$ is in $\mathrm{m}^{2} / \mathrm{Hz}, f$ is in $\mathrm{Hz}$, and $m_{n}$ is therefore in $\mathrm{m}^{2} \mathrm{~Hz}^{n}$. Significant wave height is calculated as four times the square root of the zeroth moment of the wave spectra. Peak wave period is calculated as the inverse of the peak frequency.

When $n$ is taken to be negative, wave energy associated with lower frequency is emphasized more than associated with higher frequency. The use of negative moments has been employed by Hwang et al. (2011) to facilitate the separation of swell and wind waves. This is useful in this study as it can serve as an indicator of a swell-dominated sea-state.

\subsection{Bottom sensors}

DART sensors (DART, 2020) are located 280 - $560 \mathrm{~km}$ offshore at water depths of 2805-4319 m. Water column heights are typically recorded in 15-minute intervals, although $1 \mathrm{~min}$ and $15 \mathrm{~s}$ intervals are used during special operation modes. In standard operating mode, pressure is measured at 15 -second intervals and converted to water column height, but the data is only recorded every 15 minutes and transmitted every hour. When an event is detected by its tsunami detection algorithm, i.e. when the difference between water column height based on predicted tide and the measured values exceeds a threshold (30 $\mathrm{mm}$ in North Pacific), the instrument begins operating in event mode (DART, 2020). During event mode, 15-second values are transmitted in the initial 4 minutes and 15 seconds, followed by four hours of 1-minute averages. Afterward, the system resumes standard operation if no further events are detected.

\section{Results}

\subsection{Observation of environmental conditions}

Water level observations at the coast measured by NOAA CO-OPS tide gages in 1-minute increments are shown in Figure 5. A set of water level fluctuations with frequencies higher than the tidal signal and magnitudes as high as $0.5 \mathrm{~m}$ can be seen from roughly January 16, 8:00 to January 17, 16:00 (PST, local) across all tide gages used in this study. These magnitudes of water 
Table 1. List of observations with their locations and additional information (water depth, distance to coast, data used)

\begin{tabular}{|c|c|c|c|c|c|}
\hline Name & Instrument & Measurements used & $\begin{array}{l}\text { Measurement } \\
\text { frequency }\end{array}$ & Water depth (m) & $\begin{array}{l}\text { Distance from shore } \\
\qquad(\mathrm{km})\end{array}$ \\
\hline 46419 & \multirow{4}{*}{ DART bottom sensors } & \multirow{4}{*}{ Water column height } & \multirow{4}{*}{$15 \mathrm{~min}, 1 \mathrm{~min}, 15 \mathrm{~s}$} & 2805 & 556 \\
\hline 46404 & & & & 3738 & 426 \\
\hline 46407 & & & & 3300 & 389 \\
\hline 46411 & & & & 4319 & 278 \\
\hline 46401 & \multirow{5}{*}{ NDBC buoys } & \multirow{5}{*}{$\begin{array}{l}\text { Wave height, wave } \\
\text { period, energy density } \\
\text { spectra }\end{array}$} & \multirow{5}{*}{1 hour } & 128 & 83 \\
\hline 46029 & & & & 134 & 37 \\
\hline 46050 & & & & 140 & 37 \\
\hline 46015 & & & & 400 & 28 \\
\hline 46022 & & & & 382 & 31 \\
\hline La Push & \multirow{3}{*}{ NOAA tide gages } & \multirow{3}{*}{$\begin{array}{l}\text { Water level, wind } \\
\text { speed, atmospheric } \\
\text { pressure }\end{array}$} & \multirow{3}{*}{$1 \mathrm{~min}$} & \multirow{3}{*}{ N/A (shallow) } & \multirow{3}{*}{0 (onshore) } \\
\hline $\begin{array}{c}\text { Westport } \\
\text { Garibaldi } \\
\text { South Beach } \\
\text { Charleston }\end{array}$ & & & & & \\
\hline Crescent City & & & & & \\
\hline
\end{tabular}

level fluctuations are comparable to those from meteotsunamis and even some tsunamis from earthquakes (Monserrat et al., 2006; Olabarrieta et al., 2017). These fluctuations are more intense in the northern-most (La Push) and the two southern-most tide gages (Charleston and Crescent City) than the three middle tide gages (West Port, Garibaldi, and South Beach). The water level fluctuations first increase, then are sustained around their peak level from January 16 10:00 to January 16 20:00. This period encompasses the period during which videos of large runup and injury reports took place, i.e. January 16 13:00 - January 16, 17:00. The intensity of fluctuations decreases gradually afterwards from approximately January 16 20:00 to January 17, 16:00.

Spectral analysis is performed on water level time-series from January 16 10:00 to January 16, 22:00, a period during which intense water level fluctuations persist. An examination of the energy density spectra (Figure 6) shows the existence of a common peak period at $\sim 5$ minutes across all tide gages (between 4.5 to 5.9 minutes). As described above, a video taken near Charleston during this time showed a lapse of approximately 3 minutes between the trough of a previous large wave runup and the crest of the following large wave runup, suggesting a runup period of approximately 6 minutes. Another spectral peak between approximately 13 to 22 minutes can also be seen for four (Westport, South Beach, Charleston, and Crescent City) of the six stations. These periods corresponds to periods of shelf resonance, and is further discussed in later sections. 

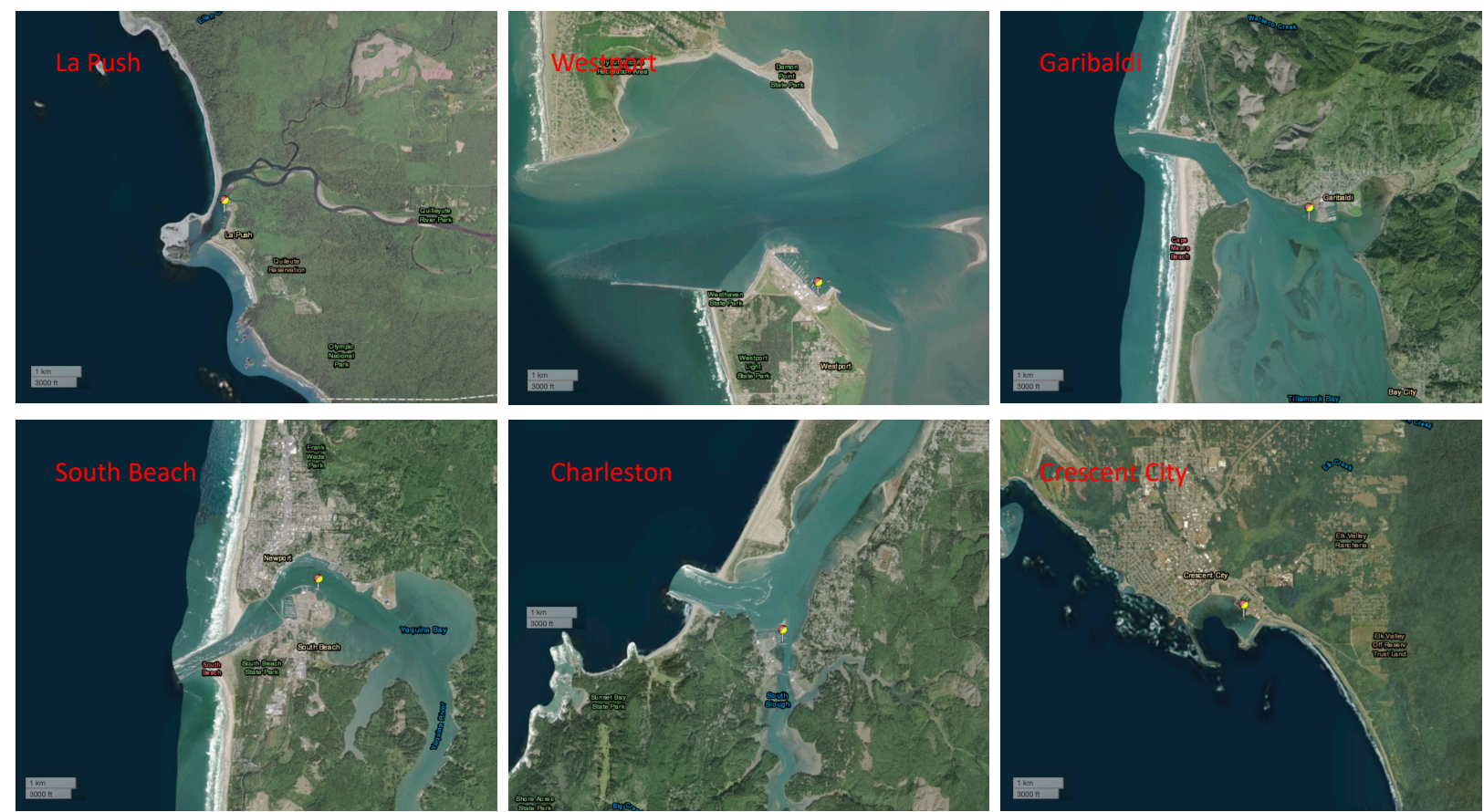

Figure 4. Locations of observation sites (from NOAA, 2020b).

Atmospheric pressure and wind speed at two tide gage locations are shown in Figure 7. Atmospheric pressure varies over a range of approximately $10 \mathrm{HPa}$ between January 15 12:00 to January 17 12:00. The majority of this variation occurs over two cycles within the two days. 1-hour high-passed time series indicate that the largest high frequency anomaly in atmospheric pressure for this period is about $1 \mathrm{HPa}$. The largest high frequency wind speed anomaly over this period is about $5 \mathrm{~m} / \mathrm{s}$ at South Beach and $2.5 \mathrm{~m} / \mathrm{s}$ at Charleston.

Significant wave height and peak wave period at NDBC buoys are shown in Figure 8. Wave height is seen to be moderately high for this region ( $\sim 4$ to $6 \mathrm{~m}$ ) at the approximate onset of the unusual water level fluctuations reported by the tide gages and throughout the time period during which videos of the large wave runups and injury reports took place. No significant anomaly in wave height was observed. However, large increases of peak wave periods (from $\sim 12$ s to $\sim 25 \mathrm{~s}$ ) were observed within the recording interval of 1 hour and very close to the approximate onset of the unusual water level fluctuations at the tide gages.

Inspection of ocean wave spectra at the NDBC buoys (Figure 9 left subplot shows an example at buoy 46015) reveal a rapid and significant growth of a low frequency peak that began close to the approximate onset of the unusual water level fluctuations at the tide gages. In a further analysis, the ocean wave spectra are partitioned into a low frequency swell component and a high frequency swell and wind component at a separation frequency of $0.06 \mathrm{~Hz}$, chosen to correspond to the low energy region between the two major peaks on January 16, 2016. The significant wave height is calculated at every hour for swell and wind components separately from the zeroth moments of each component. The resulting time series is plotted on Figure 9 

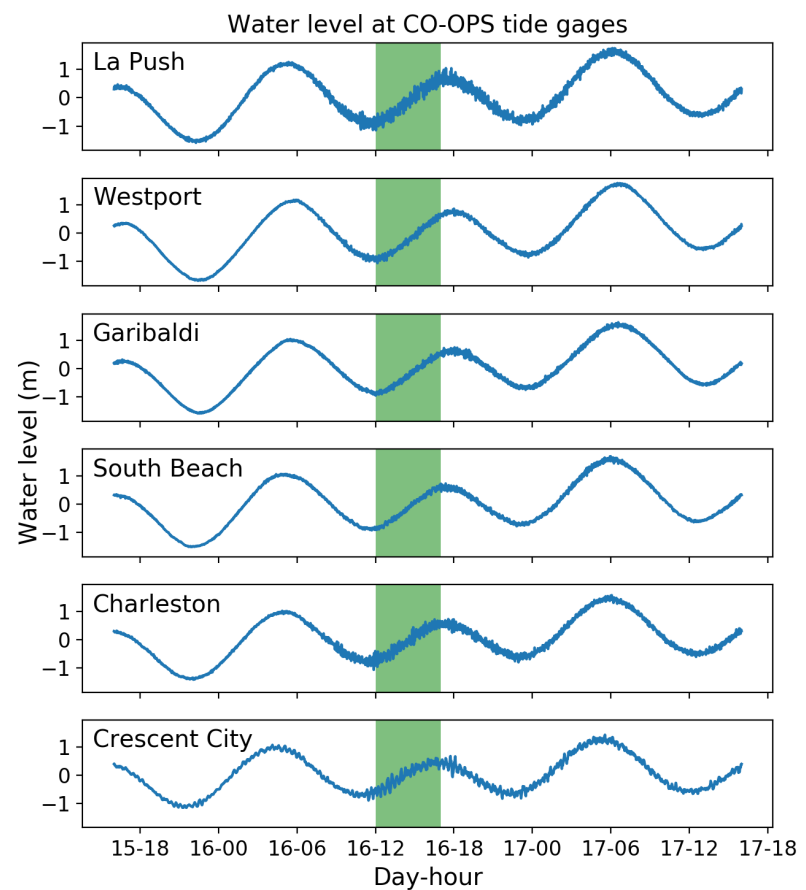
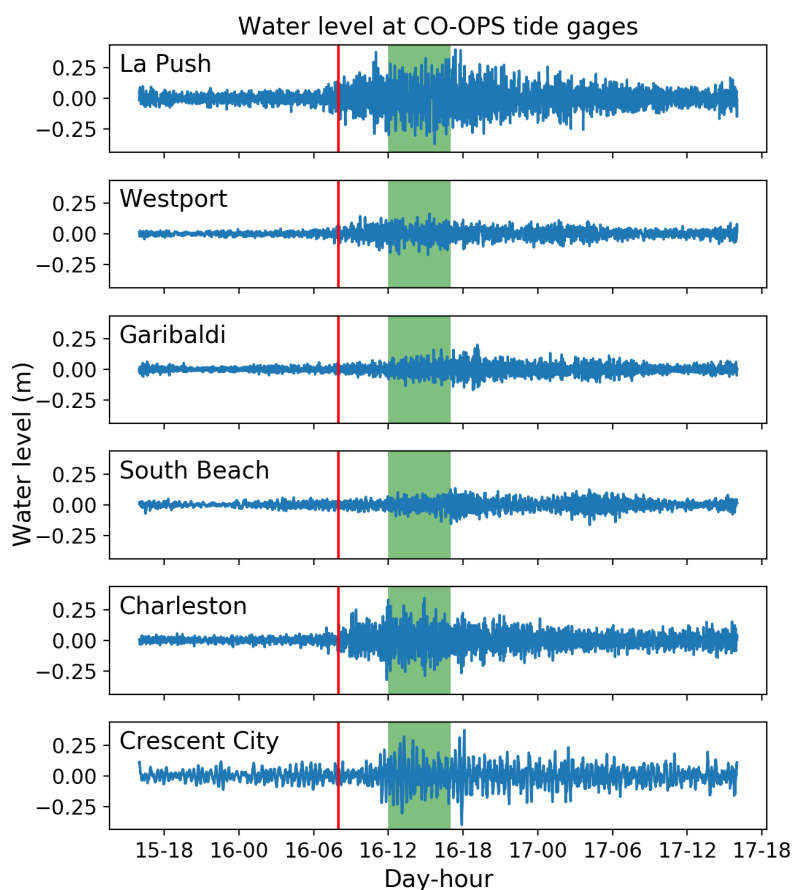

Figure 5. Water level at NOAA CO-OPS tide gages from January 16 - 18, 2016 (left, ordered north to south from top to bottom, time in PST, i.e. local). Green bar indicate duration of observed large runup events. (Right) one-hour high-passed version of the left. Red vertical line represents the approximate onset of the anomalous water level fluctuations (January 16, 8:00).

(right subplot). It can be seen that the significant wave height for the wind component does not vary considerably during the January 16 event. However, significant wave height associated with the swell component across all 5 NDBC buoys increases by approximately $5 \mathrm{~m}$ over 12 hours starting close to the onset of the unusual water level fluctuations at the tide gages.

Water column height as measured by DART sensors far offshore $(280-560 \mathrm{~km}$, Figure 3$)$ is shown in Figure 10. Fluctuations of higher-than-usual magnitudes are observed between about 4 hours (sensor 46407) to about 6 hours (sensor 46404) after the approximate onset of large water level fluctuations at the tide gages (i.e. January 16, 8:00). The increase in recording intervals starting near January 16 16:00 was due to transition from 'standard' to 'event' mode, which is triggered by the higher-thanusual magnitude of the water column height fluctuations.

\subsection{Possible generation mechanisms}

One possible generation mechanism for large runup involves trapped waves over shallow bathymetry (e.g. Sheremet et al., 2014), such as the continental shelf. On examination of the energy spectra of the onshore water level, the longer period peak (13 to $22 \mathrm{~min}$ ) is close in magnitude to that due to resonance from the shelf in this region (Allan et al., 2012). For example, Allan et al. (2012) found that the periods of shelf resonance observed after the 2011 Tohoku tsunami were between 17 minutes 

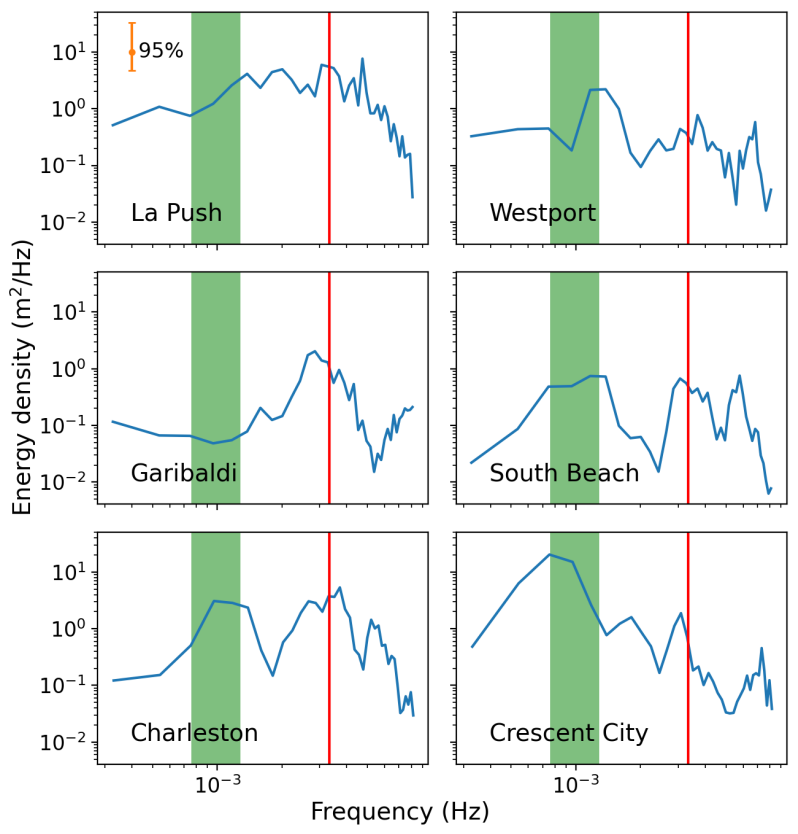

Figure 6. Energy density spectra of water level at NOAA CO-OPS tide gages from 2016 January 16, 10:00 to January 16, 22:00. Red vertical lines are located at periods of 5 minutes. Green box spans the periods between 13 to 22 minutes. Analysis is performed via Fast Fourier Transform with 18 degrees of freedom over record lengths between 708 to 715 .

and 64 minutes along the coast between Washington and Northern California. However, runup characteristics from the videos on January 16, 2016 show that the period of the runup events are closer to 5 minutes than they are to 20 minutes. In addition, large offshore directed waves were detected off the shelf (i.e. at the DART bottom sensors) hours after the initial onset of large runup events, indicating that the returning waves were able to travel past the shelf into deeper water. As such, while shelf resonance may have enhanced the runup events on January 16, they are not likely to be the primary driver.

Extreme runup can also be caused by a phenomenon known as a meteotsunami. In this mechanism, a large atmospheric disturbance travels at the shallow water speed and creates a tsunami-like runup (Monserrat et al., 2006). As described earlier, the largest atmospheric pressure anamoly from January 15 12:00 to January 17 12:00 is about $1 \mathrm{HPa}$. The wind speed anomaly over this period is about $5 \mathrm{~m} / \mathrm{s}$ at South Beach and $2.5 \mathrm{~m} / \mathrm{s}$ at Charleston. In contrast, the atmospheric pressure anomaly and wind speed that led to the meteotsunami analyzed by Olabarrieta et al. (2017) are approximately $5 \mathrm{HPa}$ and $15 \mathrm{~m} / \mathrm{s}$, respectively. Multiple meteotsunamis in the study of Monserrat et al. (2006) are also associated with atmospheric pressure anomaly of around $5 \mathrm{HPa}$. In addition, the meteotsunami events described by Olabarrieta et al. (2017) and Sheremet et al. (2016) involve one primary large wave (soliton) sometimes followed by large waves with rapidly decaying amplitudes (over a few minutes and with periods of incident waves). In contrast, the January 16, 2016 runup events, as evident by video footage and water 

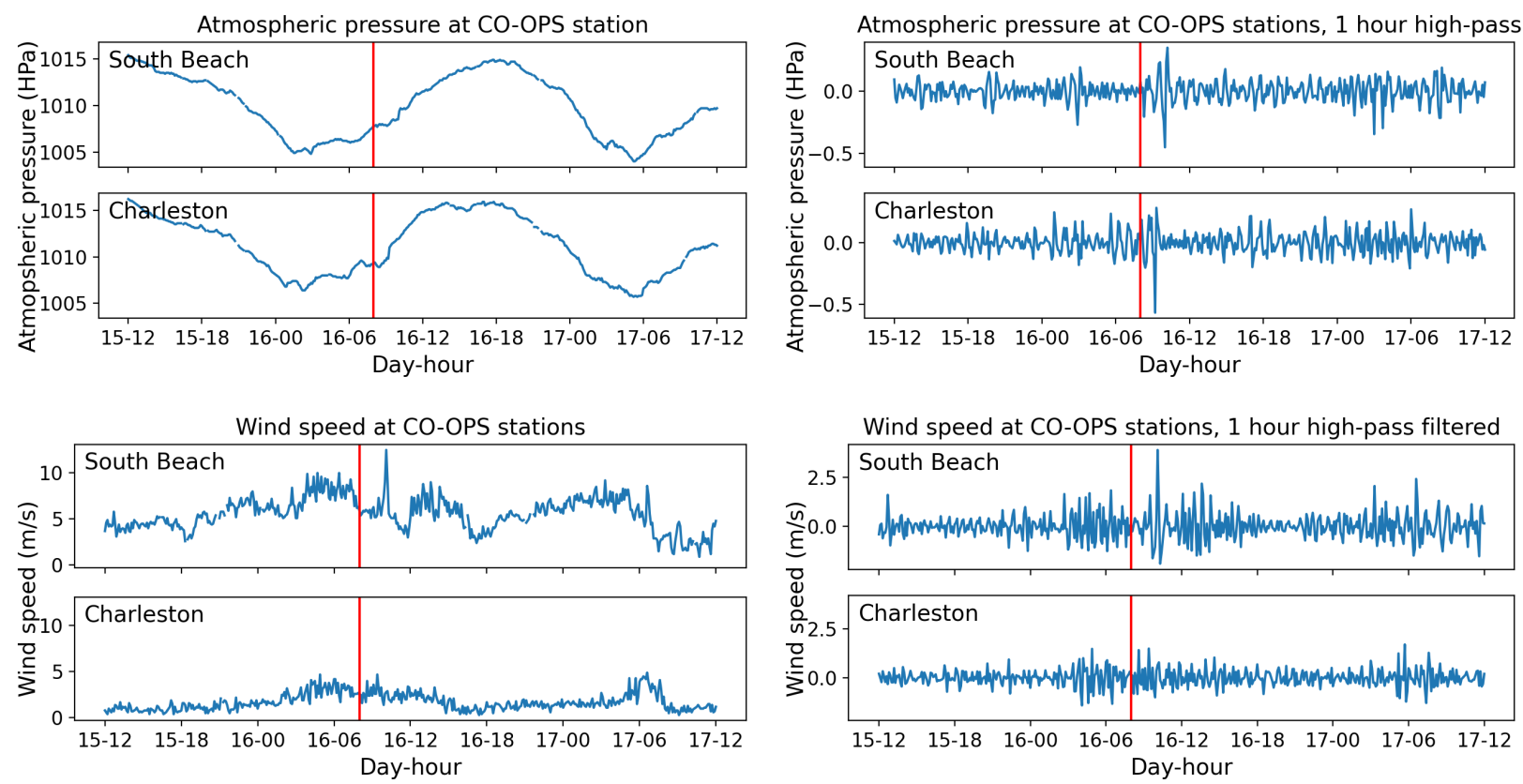

Figure 7. Atmospheric pressure and wind speed (left, top and bottom respectively) at South Beach and Charleston tide gages from January 15, 12:00 - January 17, 12:00, 2016. Red vertical lines indicate January 16, 8:00, i.e. the approximate onset of unusual water level fluctuations at the tide gages. (Right) one-hour high-passed version of the left.

level measurements, are recurring events with periods an order of magnitude larger than incident waves and with sustained amplitude over multiple hours. As such, January 16 runup events are not likely meteotsunamis due to lack of significant atmospheric pressure and wind speed anomaly, and the markedly different amplitude-decay and period characteristics than what is discussed in the meteotsunami literature.

A third possible generation mechanism is considered here. As described in the previous section, one of the most striking features of the environmental conditions leading to and during the occurence of the large runup events is the rapid and significant increase in wave energy at very low $(<0.06 \mathrm{~Hz})$ frequencies. This observation and the observation of a 5-minute period in water level response at the tide gages suggest a connection between the large runup events and infragravity waves. Specifically, it is known that infragravity waves have periods corresponding to those of wave groups, and a 5-minute period is a plausible period for wave groups when carrier waves have periods of approximately $25 \mathrm{~s}$. For example, 12 waves at $25 \mathrm{~s}$ period would make a 5-minute wave group. It is also known that infragravity waves can experience resonant growth under appropriate conditions (Longuet-Higgins and Stewart, 1964; Battjes et al., 2004). Further detail on this mechanism, as well as a method using this mechanism to forecast similar events, are in the discussion section.

Resonant growth of infragravity waves as a driver for large runup events is also supported by the observations of water column heights at the far offshore DART sensors. Specifically, the fluctuations of water column heights at the DART sensors 

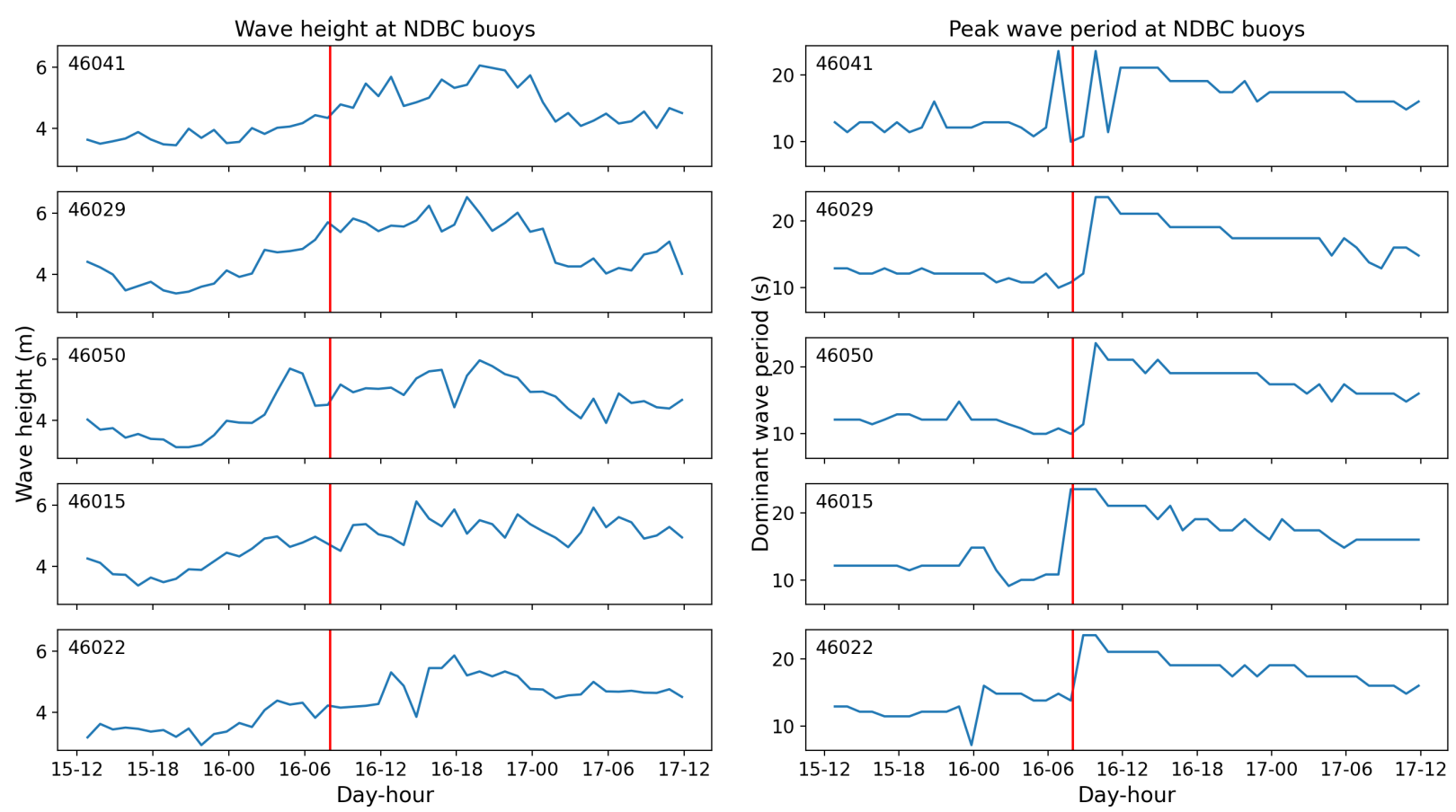

Figure 8. Significant wave height (left) and peak wave period (right) at NDBC buoys (ordered north to south from top to bottom) from January 15, 12:00 to January 17, 12:00, 2016. Data are recorded at 1-hour intervals. Red vertical lines represent January 16, 8:00, i.e. the approximate onset of unusual water level fluctuations at the tide gages.

started several hours after the approximate onset of unusual water level fluctuations at the tide gages. This suggests that the heights of the incoming infragravity waves were rather small compared to those of the reflected infragravity waves. This is also consistent with the findings that the most energetic infragravity waves in the deep ocean originate from the nearshore (Smit et al., 2018). As a test, it is assumed that the infragravity waves have a period of close to 5 minutes (from the peak in energy density spectrum of the water level at tide gages). Assuming a simple shelf bathymetry, it is estimated that these waves would take approximately 1-1.3 hours to travel from shore to the DART sensors.

\section{Discussion}

\subsection{Generation of waves with very long periods}

The large runup events of January 16, 2016 were associated with a rapid increase of peak period and energy at low frequencies (i.e. Figure 9 and Figure 10). It is thus worth discussing how incident waves of very long periods can be generated. It is known that the height and period of a deep-water wave increase as the wave stays within the wind system, or fetch (Wilson, 1955; 

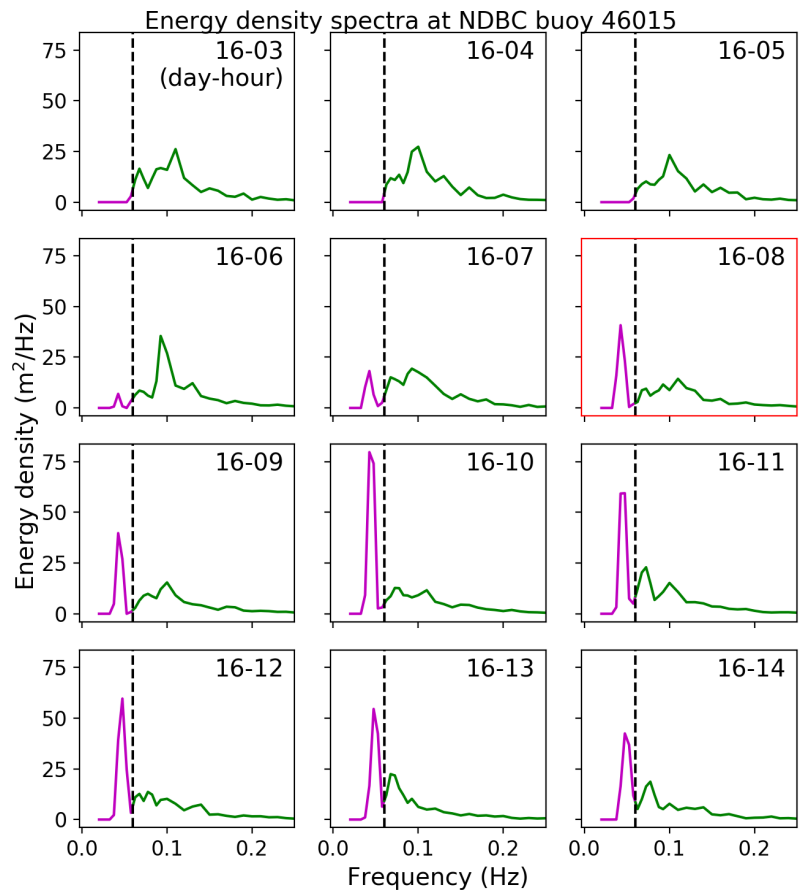

Wave heights of low frequency swell
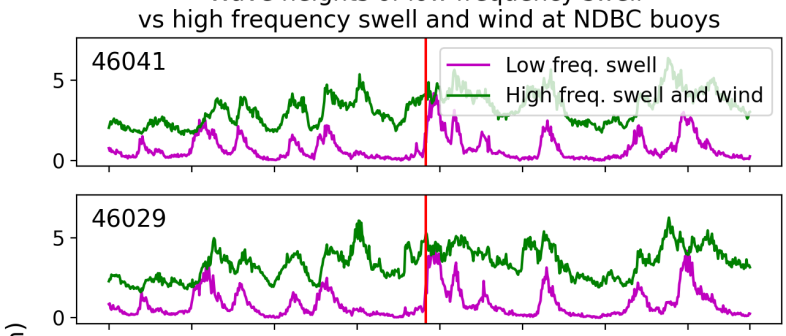

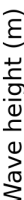
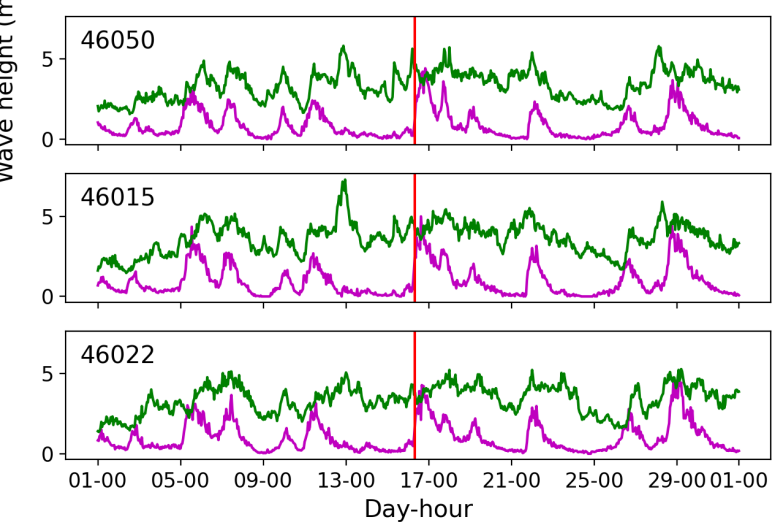

Figure 9. Ocean wave spectra (left) at NDBC buoy 46015 from January 16, 2016, 3:00 to 14:00. Vertical dash lines are located at a frequency of $0.06 \mathrm{~Hz}$ and is used to separate the swell component from the wind. Red box represents January 16, 8:00, i.e. the approximate onset of unusual water level fluctuations at the tide gages. (right) Time series of significant wave height from swell and wind components calculated from the energy density spectra on January 16. Red vertical line represents January 16, 8:00.

Bowyer and MacAfee, 2005). If the fetch moves in the same direction as the waves, the waves would remain in the fetch for a longer period than if the fetch was stationary, and thus grow to be higher and longer.

If, in addition to moving in the wave direction, the fetch also moves at speeds very close to those of the wave groups, waves of even larger heights and periods can be generated due to the longer duration in which the waves stay within the fetch. This has been referred to in the literature as trapped fetch, dynamic fetch, effective fetch, fetch enhancement, and group velocity quasi-resonance (Dysthe and Harbitz, 1987; Bowyer and MacAfee, 2005).

The likelihood of trapped fetch contributing to the January 16 runup events can be analyzed using storm tracks and wave periods.

Figure 12 (left) shows the storm track on January 16, 2016. Wave periods reported by the offshore NDBC buoys range from $19 \mathrm{~s}$ to $23.5 \mathrm{~s}$ between 2016 January 16 13:00 and 2016 January 16 17:00, during which time videos of large runup and injury reports took place (Figure 6). Using the deep-water dispersion relationship, the resulting wave group speeds were approximately $53 \mathrm{~km} / \mathrm{hr}$ to $66 \mathrm{~km} / \mathrm{hr}$. By measuring distances between centers of the storms at different times it is estimated that the fetch regions were traveling at $57 \mathrm{~km} / \mathrm{hr}$. Furthermore, peak wave directions were about 265 deg clockwise from north, and 


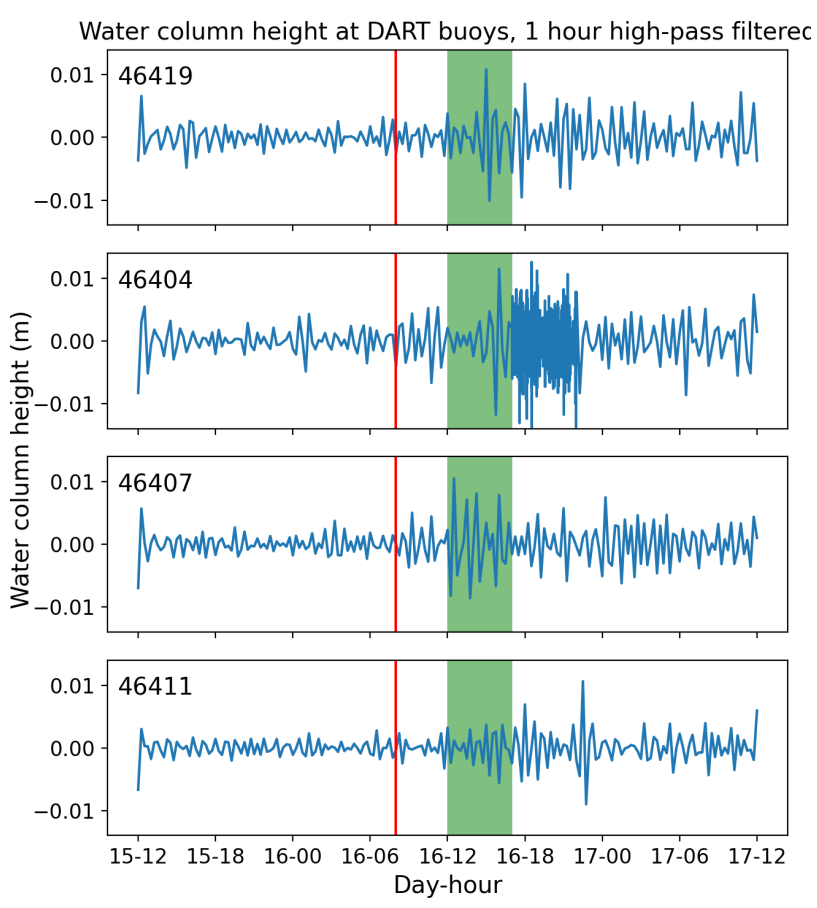

Figure 10. Water column height deviations (1-hour high-pass filtered) at DART sensors from January 15, 12:00 - January 17, 12:00, 2016. Red vertical lines represent January 16, 8:00, i.e. the approximate onset of unusual water level fluctuations at the tide gages. Green bars indicate time period during which videos of large runup and injury reports took place, i.e. between January 16 12:00 to January 16 17:00. Between approximately January 16 17:00 to January 16 22:00, the 46404 station was in higher sampling mode.

are in reasonable alignment with the tracks of the storms. Therefore, trapped fetch was likely to be at least partially responsible for the January 2016 events.

As large as the January 16, 2016 runup events were, they were not the only occurence of extreme runup in this region. On January 18, 2018, video footage (YouTube, 2020f) was taken at a coast of the PNW (Figure 11) that shows recurring extreme runup events with similar characteristics on this day compared to January 16, 2016. Figure 12 (right) shows the storm track on January 18, 2018. Similar large fluctuations were also observed at the tide gages, NDBC buoys, and DART bottom sensors on January 18, 2018 (not shown). From 2018 January 18 8:00 to 2018 January 18 17:00, i.e. approximate time of sunrise to sunset on January 18, 2018, the wave periods ranged between $16 \mathrm{~s}$ to $19 \mathrm{~s}$. The corresponding wave group speeds are approximately $45 \mathrm{~km} / \mathrm{hr}$ to $53 \mathrm{~km} / \mathrm{hr}$. Analysis of the storm track shows that the storm was traveling at $53 \mathrm{~km} / \mathrm{hr}$. Peak wave directions were about 238 deg from north, which is also in reasonable alignment with the storm track. Thus, trapped fetch was likely to be in effect for the January 2018 events as well. 


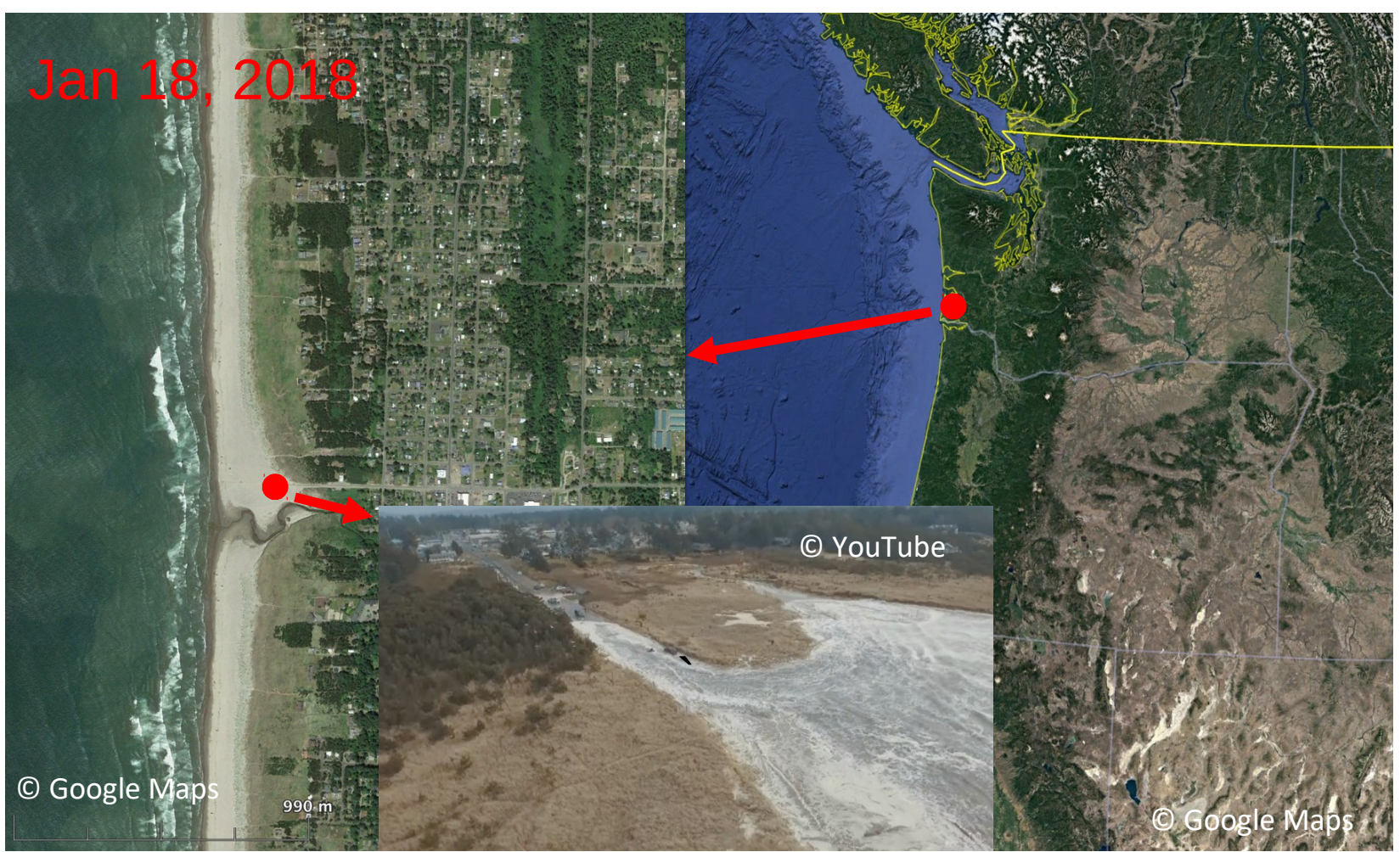

Figure 11. Location and a photograph from an extreme runup event on January 18, 2018 (satellite images from Google Maps, insert from YouTube, 2020f).

While it is plausible that a very large and very strong storm could potentially generate waves of very long periods without having a trapped fetch, the trapped fetch provides a mechanism for lesser storms to generate waves of long enough periods to lead to the type of large runup events shown in this study.

\subsection{Resonant growth of infragravity waves}

As shown in Figure 6, a common peak period at approximately 5 minutes is seen in the energy density spectra of the large water level fluctuations at all 6 tide gages along the PNW on January 16, 2016. In addition, a period of approximately 6 minutes can be deduced from one of the videos taken on that day (YouTube, 2020a). A period of approximately 5-6 minutes is also a plausible time-scale for wave groups.

Wave motions with periods in the time-scales of wave groups have long been known to exist (e.g. Munk, 1949; Tucker, 1950). Two mechanisms are known to generate such waves. In the first mechanism, variations of amplitudes within a wave group lead to transfer of momentum in such a way that produces a depression of the mean water level at the location of waves with greater amplitudes and an elevation of mean water level at the location of waves with smaller amplitudes. This so-called 'bound infragravity wave' travels at the speed of wave groups towards shore and as a free wave away from shore after reflection 

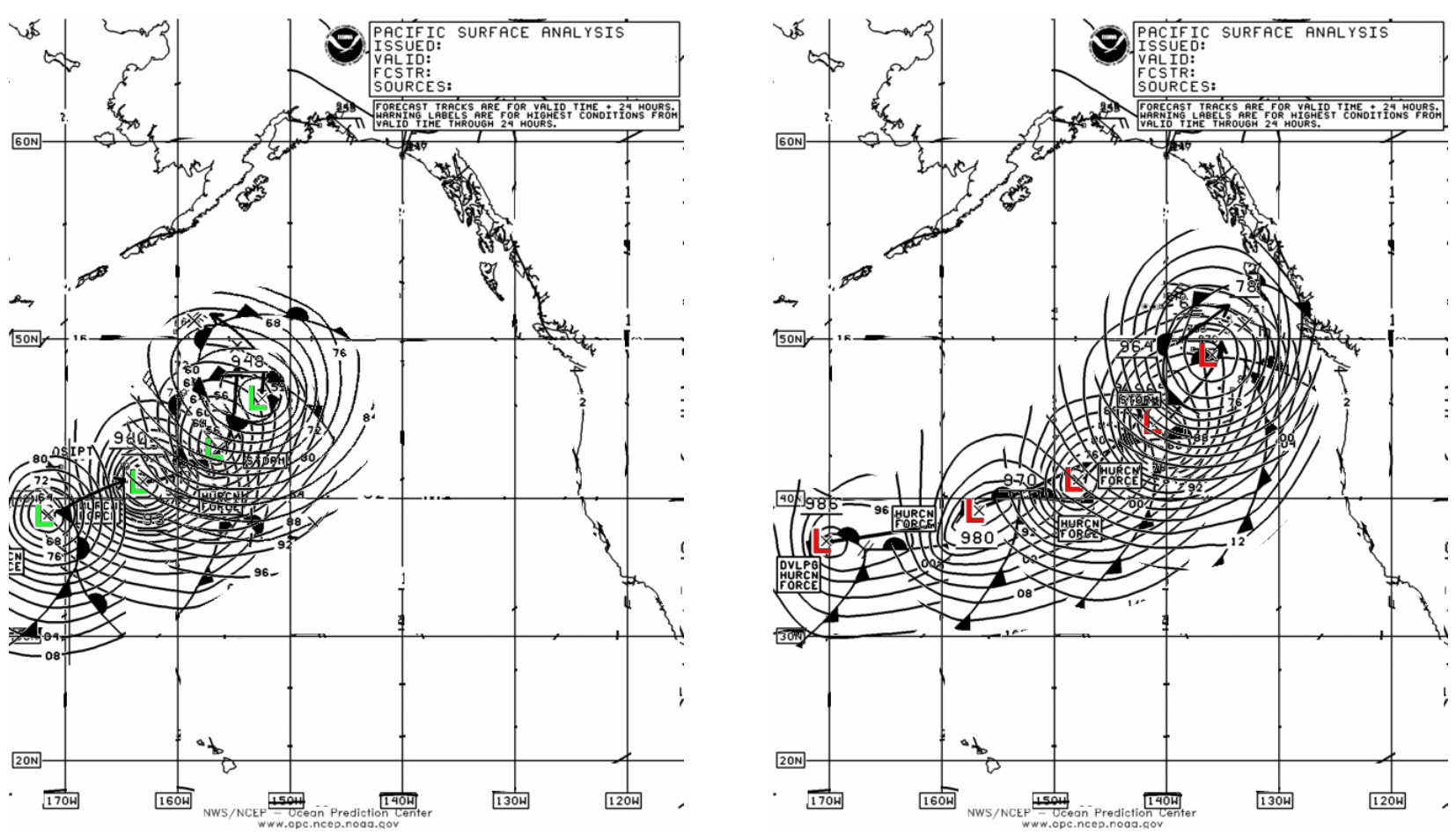

Figure 12. Storm tracks for January 16, 2016 (left) and January 18, 2018 (right). L represents center of storm (Elson, 2018).

(Longuet-Higgins and Stewart, 1964). In the second mechanism, changes in the cross-shore location of wave breaking releases a free wave towards the shore (Symonds et al., 1982). The relative importance of the second mechanism is known to decrease with decreasing beach slope (List, 1992; Battjes et al., 2004). This suggests that in the case of relatively low beach slope (as is in this study), the first mechanism is important.

The amplitudes of bound infragravity waves increase shoreward differently compared to free waves. When the carrier wave length is small compared to the water depth, but the group wave length is large compared to the water depth, the infragravity wave amplitude - according to the theory of radiation stress - is (Longuet-Higgins and Stewart, 1964)

$a_{g}=\frac{a^{2} k}{4 k h-1}$

where $a_{g}$ is the infragravity wave amplitude, $a$ is the carrier wave amplitude, and $k$ is the carrier wavenumber.

When the carrier waves are in shallow water, i.e. their length is much greater than the water depth, the amplitudes of the bound infragravity waves approach resonance, and the variations of amplitudes with water depth are bound between $\propto h^{-1 / 4}$ and $\propto h^{-5 / 2}$ (e.g. Longuet-Higgins and Stewart, 1962; Battjes et al., 2004). This is in contrast to the shoaling of free waves in shallow water, which varies as $\propto h^{-1 / 4}$. The resonant growth of bound infragravity waves in shallow water is due to energy transfer from the incident waves to the infragravity waves. When the bottom slope is steep compared to the infragravity wave length, little to no energy transfer exists, and the infragravity wave shoals close to $h^{-1 / 4}$. When the bottom slope is mild 
compared to the infragravity wave length, a great amount of energy transfer takes place, and the infragravity waves increase in ampltudes close to $h^{-5 / 2}$, i.e. at a much greater rate compared to free waves. Battjes et al. (2004) proposed the following parameter, the normalized slope, as a controlling parameter on the growth of infragravity waves:

$\beta=\frac{h_{x}}{\omega} \sqrt{\frac{g}{h}}$

where $h_{x}$ is a characteristic bed slope, $\omega$ is the radial frequency of the infragravity wave, and $h$ here is a characteristic water depth. The results of van Dongeren et al. (2007) confirmed that infragravity wave amplitudes vary close to $\propto h^{-5 / 2}$ when $\beta$ is small. This growth rate decreases as $\beta$ increases, and eventually approaches $\propto h^{-1 / 4}$ for large $\beta$. It is readily apparent from (3) that shorter infragravity waves are associated with a smaller $\beta$. It would seem contradictory, then, that the extreme runup events of January 16, 2016 occured when the infragravity waves were very long.

To examine the growth of infragravity wave amplitudes from deep to shallow water for different carrier wave periods, a simple model is used. This model assumes a planar bed with constant slope and alongshore uniformity. It employs simple dynamical constraints for the purpose of computing general trends for waves with differing periods. Infragravity wave amplitudes are computed from deep water to the depth at which infragravity waves start to break. Infragravity wave amplitude in deep water follows (2). Carrier wave amplitudes are computed from linear water wave theory. In shallow water, $a_{g} \propto h^{-\alpha}$ as described earlier, where $\alpha$ depends on $\beta$ - defined in (3) - and is between $-1 / 4$ and $-5 / 2$. The characteristic depth $h$ in (3) is taken to be the carrier wave breaking depth, which is determined from the criterion $H_{b}=\kappa h_{b}$, where $H_{b}$ is the breaking wave height, $h_{b}$ is the breaking depth, and $\kappa$ is an empirical parameter, taken to be 0.78 . The dependence of $\alpha$ on $\beta$ is obtained from the laboratory and numerical results of van Dongeren et al. (2007, Figure 2). The nearshore slope is taken to be 0.01 (Cohn et al., 2019) and the carrier wave amplitude is taken to be $2.5 \mathrm{~m}$ (Figure 8). A carrier wave period of $25 \mathrm{~s}$ is chosen to correspond to the peak incident wave period during the large runup events. The results are compared with those from a carrier wave period of $10 \mathrm{~s}$, which is representative of wave periods only hours before the first large runup occurrence.

The result from this simple model shows that $25 \mathrm{~s}$ carrier waves enter shallow water at a water depth of $15 \mathrm{~m}$. The corresponding infragravity wave amplitude is $0.87 \mathrm{~m}$. In contrast, for carrier waves of $10 \mathrm{~s}$, the infragravity wave amplitude at this depth is $0.13 \mathrm{~m}$. For carrier waves of $25 \mathrm{~s}$, the infragravity wave resonant growth follows $a_{g} \propto h^{-1.0}$ and reaches a maximum amplitude of $2.3 \mathrm{~m}$ at a depth of $5.8 \mathrm{~m}$. For carrier waves of $10 \mathrm{~s}$, the infragravity wave amplitude at this depth is $0.44 \mathrm{~m}$. The resonant growth of infragravity waves follows $a_{g} \propto h^{-1.5}$ for carrier waves of $10 \mathrm{~s}$, but are limited by the fact that the carrier waves reach shallow water at $2.4 \mathrm{~m}$ water depth and begin to break at $1.8 \mathrm{~m}$. This result in a maximum infragravity wave amplitude of $0.69 \mathrm{~m}$ for carrier waves of $10 \mathrm{~s}$.

Another factor that contributes to the increase in runup magnitude at lower carrier wave frequencies can be attributed to the reduction of energy dissipation. It has been suggested by Battjes et al. (2004) and confirmed by van Dongeren et al. (2007) that the energy dissipation of bound infragravity waves depend on the following parameter:

$\beta_{H}=\frac{h_{x}}{\omega} \sqrt{\frac{g}{H}}$ 
where $H$ is the infragravity wave height near the shoreline. It can be seen that $\beta_{H}$ is similar to the previously defined $\beta$, except for the replacement of $h$ with $H$. van Dongeren et al. (2007) find that at very low values of $\beta_{H}$, the reflection coefficient of the infragravity waves is close to 0 , indicating near complete energy dissipation. As $\beta_{H}$ increases, the reflection coefficients also increase until they approach close to 1 , indicating near absence of energy dissipation. The low value of $\omega$ observed during the large runup events in this study thus acts to reduce energy dissipation of the bound infragravity wave, leading to larger runup events. To illustrate this effect, the maximum infragravity wave heights from the previous comparison are used in (4), and the resulting $\beta_{H}$ is related to reflection coefficients from the experiments of van Dongeren et al. (2007, Figure 3). This yields reflection coefficients of 0.50 and 0.40 for carrier wave of $25 \mathrm{~s}$ and $10 \mathrm{~s}$, respectively.

In summary, infragravity wave amplitudes near the shore are considerably larger for carrier waves of $25 \mathrm{~s}$ than those for carrier waves of $10 \mathrm{~s}$. In addition, infragravity waves associated with $25 \mathrm{~s}$ carrier waves also experience less energy dissipation than those associated with $10 \mathrm{~s}$ carrier waves. Both of these effects imply enhancements in wave runup.

The plausibility of maintaining a high infragravity wave growth rate and reasonably low energy dissipation is also supported by observations at the DART sensors (Figure 10). It is seen that the large fluctuations of water column height occur hours after the first occurrence of large water level fluctuations at the shore. This suggests that the incoming infragravity waves, before growth and energy dissipation occurs in the nearshore, are not large enough to cause a significant response at the sensors; whereas the outgoing infragravity waves are able to produce a significant response due to having achieved a reasonable growth and reasonably low energy dissipation before being reflected away from shore. And as stated earlier, this is also consistent with the finding that the most energetic infragravity waves in the deep ocean originate from the nearshore (Smit et al., 2018).

\subsection{A predictor for large runup events due to bound infragravity waves}

As shown in the results section, an important observation of the January 16 large runup events is that these events are connected with rapid growth of wave energy in very low frequencies. This connection can be exploited to explore a predictive tool for similar large runup events. The goal of this predictor is to use a metric of ocean waves to predict a metric of water levels at the shore. One approach to this is to use a cutoff frequency to identify the low frequency component of the ocean wave spectra. However, it was found that the subjectivity of the cutoff frequency makes the predictor less robust. Instead, we explored an approach that uses the negative moments of the ocean wave spectra. In this approach, negative moments (1) at NDBC buoys were correlated to representative measures of the intensity of water level fluctuations at the tide gages. NDBC and tide gage pairs were determined based on proximity. To represent moments of the ocean energy spectra, normalized and non-normalized moments were evaluated. Water levels RMS - hereinafter referred to as $\eta_{\mathrm{nms}}$ - was chosen to represent the magnitude of the water level fluctuations. The best relationship was found between $\eta_{\mathrm{nms}}$ and the non-normalized moments $\sqrt{m_{-3}}$. Although $\sqrt{m_{-3}}$ has rather odd units in $\mathrm{m} / \mathrm{Hz}^{3 / 2}$, it was found to be a better predictor of $\eta_{\mathrm{rms}}$ than normalized moments, including $\sqrt{m_{-3} f_{p}^{3}}, \sqrt{m_{-3} f_{m}^{3}}$, and $\sqrt{m_{-3} f_{m_{2}}^{3}}$, where $f_{p}, f_{m}$, and $f_{m_{2}}$ are peak, mean, and zero-upcrossing frequencies, respectively. 345 It was also found that the use of $\sqrt{m_{-3}}$ produced a considerablly improved predictor of $\eta_{\mathrm{rms}}$ compared to $\sqrt{m_{0}}$ (e.g. $R^{2}$ from using $\sqrt{m_{0}}$ and $\sqrt{m_{-3} f_{m}^{3}}$ are 0.55 and 0.79 , respectively, for 46041-La Push for years 2016-2018). Figure 13 shows $\eta_{\mathrm{nms}}$ and $\sqrt{m_{-3}}$ for year 2016 . 

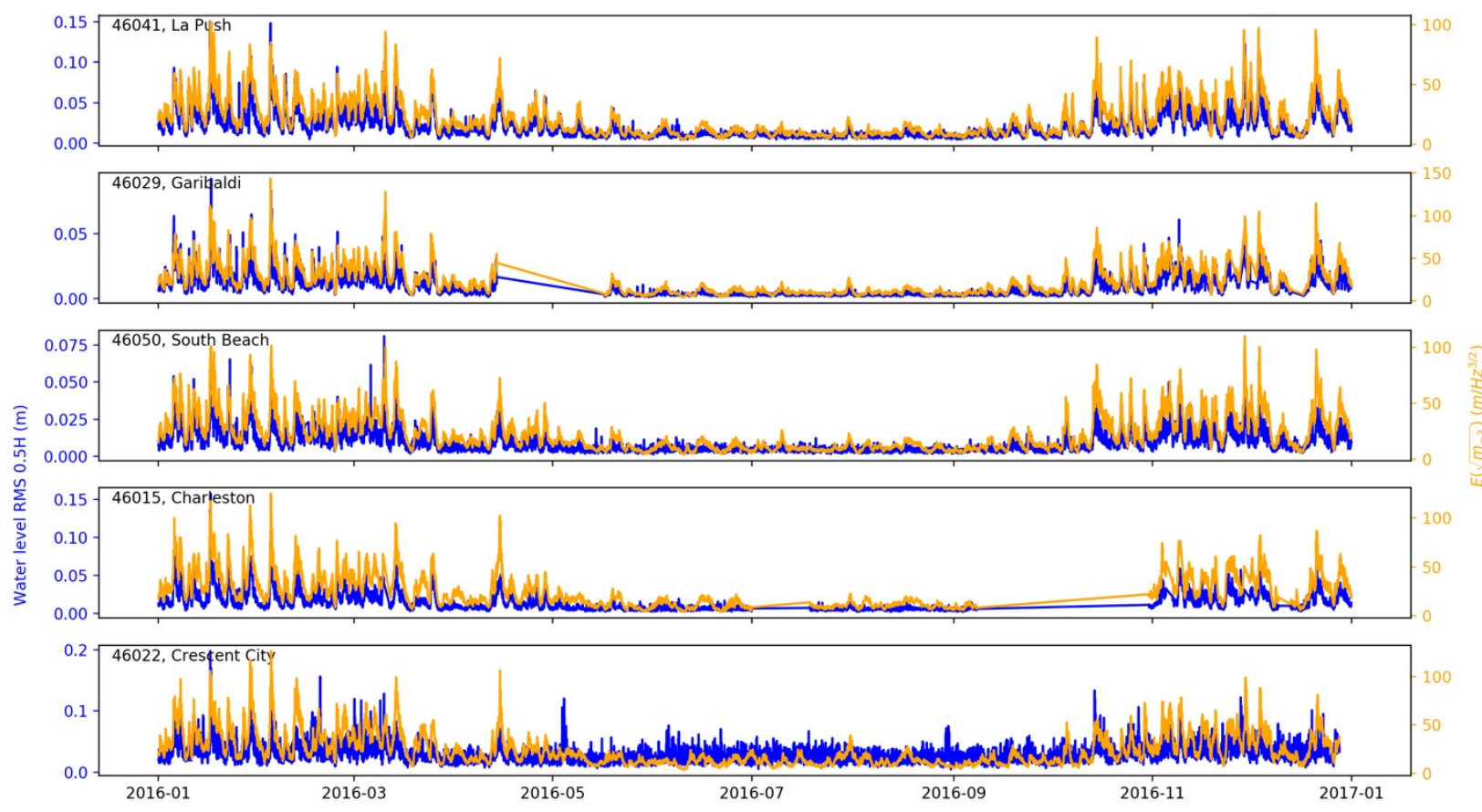

Figure 13. $\sqrt{m_{-3}}$ of the offshore ocean wave spectra and $\eta_{\mathrm{rms}}$ computed using a 0.5 -hour window length for year 2016 .

To test the effectiveness of the predictor, both the January 16, 2016 the January 18, 2018 events are used. Figure 14 shows the quantity $\sqrt{m_{-3}}$ versus $\eta_{\mathrm{rms}}$ for years 2016 to 2018, with red dots representing time periods during the January 16, 2016 and green dots representing January 18, 2018 from sunrise to sunset. A linear relationship is seen between $\sqrt{m_{-3}}$ and $\eta_{\mathrm{rms}}$ for 4 out of the 5 sites.

It should be noted that the fitted slopes of the relationship vary considerably among some of the sites. For example, at La Push-46041, the slope is $9.29 \times 10^{-4}$, whereas at Garibaldi-46029 the slope is $4.4 \times 10^{-4}$. However, the slopes are similar from year to year at each site. For example, the slope at La Push-46041 is $9.77 \times 10^{-4}, 9.04 \times 10^{-4}$, and $8.73 \times 10^{-4}$ for years 2016, 2017, and 2018 respectively. The fit is reasonable at four out of the five sites, i.e. $R^{2}$ is between 0.78 and 0.80 at La Push46041, Garibaldi-46029, and Charleston-46015, and is 0.72 at South Beach-46050. However, the fit is rather poor at Crescent City-46022 with $R^{2}$ of 0.23 . Crescent City's harbor, which is where the tide gage is located, is known to be susceptible to wave resonance from the shelf (Allan et al. 2012, Lu et al. 2014 and Figure 6). Aside from 46022-Crescent City, the other four sites all show high values of $\sqrt{m_{-3}}$ and corresponding high values of $\eta_{\mathrm{rms}}$ during time periods for the January 16, 2016 and January 18, 2018 which lends confidence in using this relationship as a predictor for similar extreme runup events.

As an example application, a threshold of $\sqrt{m_{-3}}=75\left(\mathrm{~m} / \mathrm{Hz}^{3 / 2}\right)$ is chosen at station Garibaldi-46029. Using the established relations from Figure 14, $\sqrt{m_{-3}}$ greater than the above threshold would then indicate large runup events. This metric would 

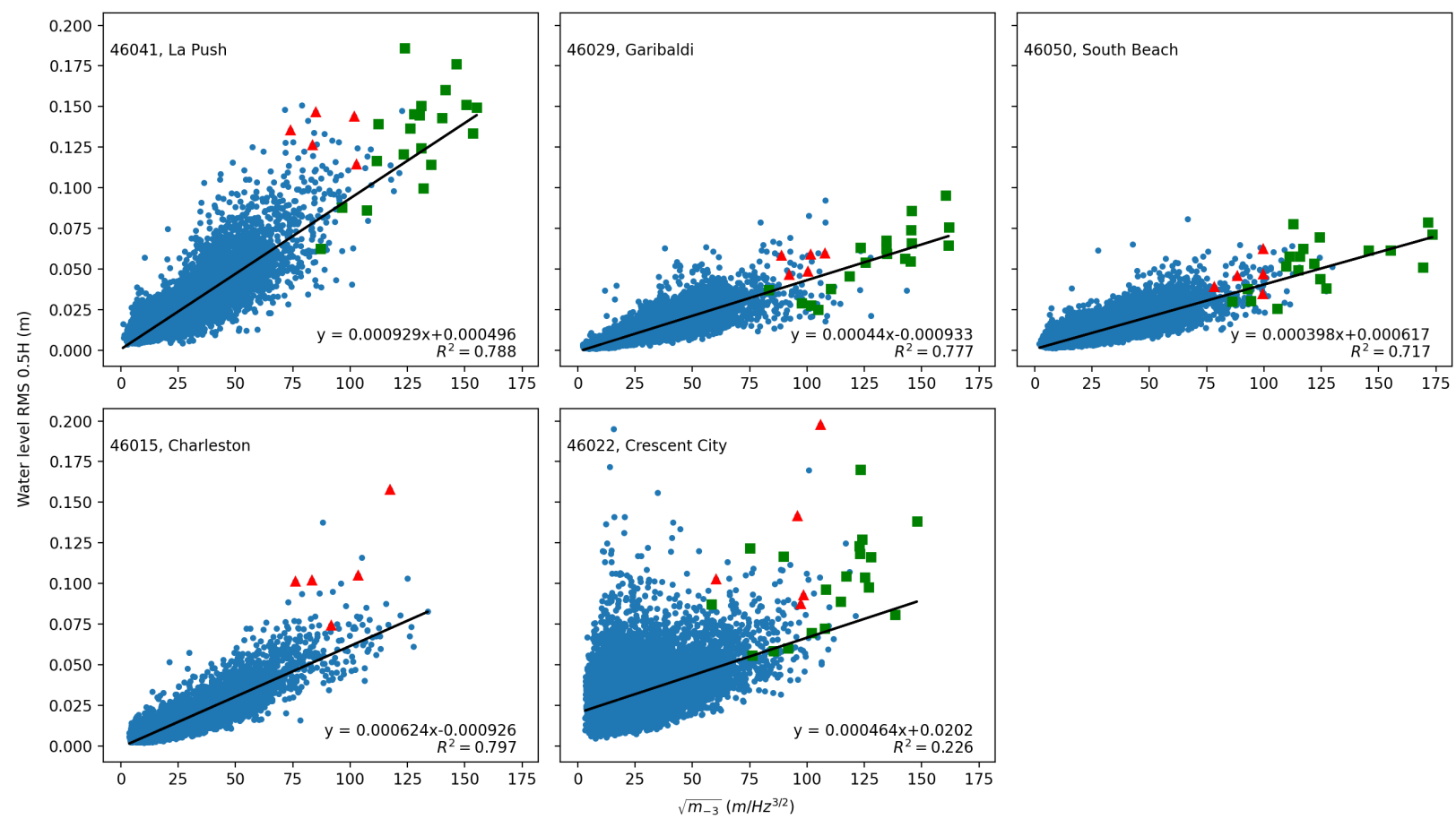

Figure 14. Onshore Water level RMS using a 0.5-hour window length at the tide gages versus $\sqrt{m_{-3}}$ of the offshore ocean wave spectra for year 2016 to 2018. Red dots correspond to the duration between 2016 January 16 13:00 to 2016 January 16 17:00, i.e. time during which video recordings of large runup and injury reports took place. Green dots represent the duration between and 2018 January 18 8:00 to 2018 January 18 17:00, which represents a period during another series of extreme runup events has been captured on video.

identify $1.3 \%$ of the period between 2016 and 2018 as potentially having large runup events and would include both the January 2016 and January 2018 events.

Figure 15 shows the monthly means of $\sqrt{m_{-3}}$ and $\eta_{\mathrm{rms}}$ for years 2016-2018 at each site. It it seen that for four out of the five sites (except Crescent City-46022), the monthly means of both $\sqrt{m_{-3}}$ and $\eta_{\mathrm{rms}}$ during the winter months can be as high as more than triple of those during the summer months. For example, during the month of January the mean of $\sqrt{m_{-3}}$ and $\eta_{\mathrm{rms}}$ at La Push-46041 are $35.8 \mathrm{~m} / \mathrm{Hz}^{3 / 2}$ and $0.035 \mathrm{~m}$, respectively, whereas they are $9.9 \mathrm{~m} / \mathrm{Hz}^{3 / 2}$ and $0.0028 \mathrm{~m}$, respectively, during the month of August. This suggest that the type of extreme runup events discussed in this work occur much more frequently during winter months than they occur during summer months.

One reason why large runup events due to bound infragravity waves may occur much more frequently during the winter months than they do in the summer months is related to the fact that the wave periods in this region is much greater in the winter months than they are in the summer months. An increase in the length of the infragravity wave acts to reduce its growth as it approaches shore but also acts to reduce its energy dissipation. This may facilitate a more optimal balance between growth and energy dissipation of the infragravity wave as discussed before. 


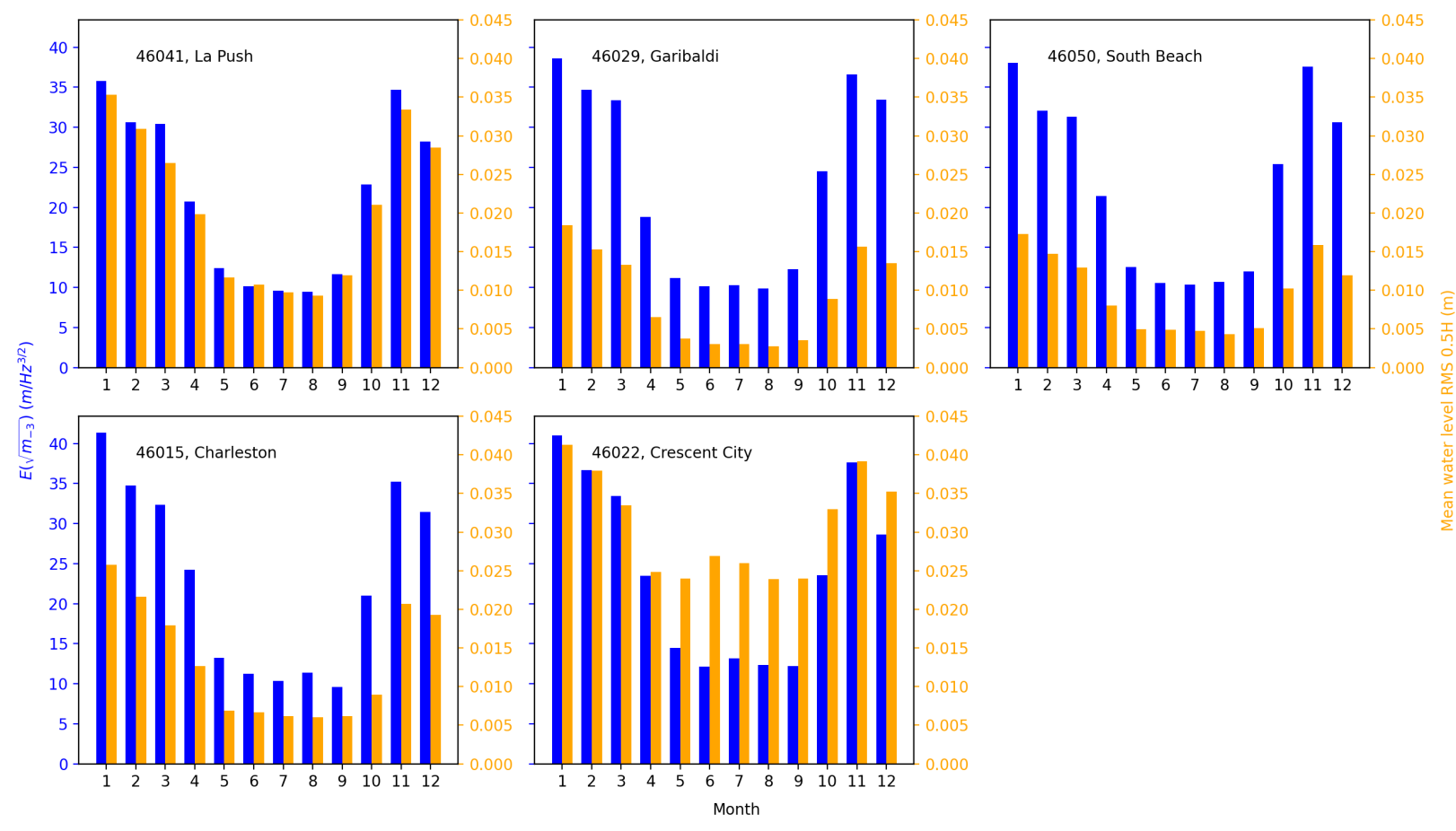

Figure 15. Mean water level RMS (orange) at various NOAA CO-OPS stations and $\sqrt{m_{-3}}$ (blue) of the energy density spectra at their corresponding NDBC buoys in 2016.

\section{Conclusions}

This work presents an analysis of observations of unusually large runup events that occurred along the PNW coast on January 16, 2016. On this day, video recordings and injury reports document multiple extreme runup events - with horizontal excursions exceeding a hundred meters and periods of minutes - occurring along approximately $1000 \mathrm{~km}$ of coastline within 5 hours of each other. Environmental conditions leading up to and during the large runup events are presented.

The observations show that the large runup events are strongly associated with a rapid increase in wave energy at low frequencies, i.e. the arrival of incident waves with very long periods. In addition, water level measurements at the tide gages show a $\sim 5$ min peak period during this time. The arrival of incident waves with very long periods can be explained by the existence of trapped fetch, which occurs when the fetch moves in the same direction and at speeds close to those of the waves groups. Analysis of storm tracks show that trapped fetch was indeed in effect for this event leading to the large runup events. The $\sim 5$ min peak period at the tide gages suggest a link to wave groups and infragravity waves. It is shown using a simple model that a very large carrier wave period results in a very large infragravity wave amplitude at the shore yet maintaining reasonably low energy dissipation. This explanation is supported by far offshore bottom sensors, which did not detect the incoming infragravity waves but did detect the returning ones, even at 3 to $4 \mathrm{~km}$ depth. 
https://doi.org/10.5194/nhess-2020-425

Preprint. Discussion started: 26 January 2021

(c) Author(s) 2021. CC BY 4.0 License.

(c) (i)

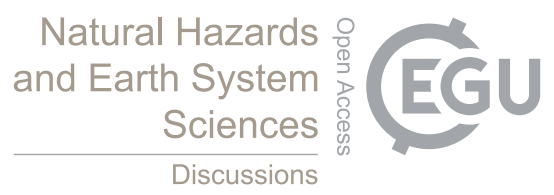

Using the link between low frequency wave energy and large runup events, a predictor for similar types of large runup events is developed. The predictive ability is seen to be reasonable for 4 out of the 5 tide gages used in the study, and for two different sets of large runup events. Results from this predictive method suggest that the type of large runup events discussed in this work tend to occur much more frequently in the winter months than they do in the summer months (Tillotson and Komar, 1997, and Figure 1). This is likely owing to the fact that the wave periods are much longer during the winter months (e.g. median = $12.9 \mathrm{~s}$ in January) than they are in the summer months (e.g. median $=8.3 \mathrm{~s}$ in August). This would result in longer infragravity waves and larger associated runup. The performance demonstrated by this predictive method may be helpful to future efforts in developing forecasting tools for extreme runup events, with the aim of issuing warnings to the public.

Data availability. The data used in this work are publicly available via sources referenced.

Video supplement. The videos referenced in this work are available as cited.

400 Author contributions. Özkan-Haller, Holman, and Ruggiero acquired funding for this work. Ozkan-Haller formulated the research goals and supervised the execution of the research. Holman and Ruggiero provided comments on the manuscript. Jensen, Elson, and Schneider contributed to the provision of data used in this research and provided research ideas. García-Medina contributed to research ideas and facilitated the investigation. Li carried out the investigation and prepared the manuscript with contributions from all co-authors.

Competing interests. The authors declare that they have no conflict of interest.

Acknowledgements. This work was funded by the National Science Foundation under award OCE-1459049. The authors also thank Jeremiah Pyle, Tyree Wilde, Sven Nelaimischkies, Brian Nieuwenhuis, Troy Nicolini, David Bright, John Lovegrove, and others at the National Weather Service for their collaboration. Thanks are also given to Peter Nielsen and Andrew Kennedy for their helpful comments and suggestions. 
https://doi.org/10.5194/nhess-2020-425

Preprint. Discussion started: 26 January 2021

(C) Author(s) 2021. CC BY 4.0 License.

\section{References}

Allan, J. C., Komar, P. D., Ruggiero, P., and Witter, R.: The March 2011 Tōhoku Tsunami and its impacts along the U.S. West Coast, R. J. Coast. Res., 28(5), 1142-1153, 2012.

Baldock, T. E., and Holmes, P.: Swash hydrodynamics on a steep beach, Coastal Dynamics - Proc. Intern. Conf., ASCE, $784-793,1997$.

Battjes J. A.: Computation of set-up, longshore currents, run-up and overtopping due to wind-generated waves, Delft Univ. of Tech., Dep. of Civil Eng., Tech. Rep. No. 74-2, 1974.

Battjes, J. A., Bakkens, H. J., Janssen, T. T., and van Dongeren, A. R.: Shoaling of subharmonic gravity waves, J. Geophys. Res.: Oceans, 109, C02009, 2004.

Blenkinsopp, C. E., Matias, A., Howe, D., Castelle, B., Marieu, V., and Turner, I. L.: Wave runup and overwash on a prototype-scale sand barrier, Coast. Eng., 113, 88-103, 2016.

Bowyer, P. J., and MacAfee, A. W.: The theory of trapped-fetch waves with tropical cyclones - an operational perspective, Wea. Forecasting, 20, 229-244, 2005.

Cohn, N., Ruggiero, P., García-Medina, G., Anderson, D., Serafin, K. A., and Biel, R.: Environmental and morphologic controls on waveinduced dune response, Geomorphology, 329, 108-128, 2019

Deep-ocean Assessment and Reporting of Tsunamis (DART): https://nctr.pmel.noaa.gov/Dart/, last access: 5 Oct 2020

Dewey, J. F., Ryan, P. D.: Storm, rogue wave, or tsunami origin for megaclast deposits in western Ireland and North Island, New Zealand?,

Proc. Nat. Acad. Sci., National Academy of Sciences, 114, E10639-E10647, 2017.

Di Leonardo, D., and Ruggiero, P.: Regional scale sandbar variability: Observations from the U.S. Pacific Northwest, Cont. Shelf. Res., 95, 74-88, 2015.

Dysthe, K. B., and Harbitz, A.: Big waves from polar lows? Tellus, 39A, 500-508, 1987

Elson, D. B.: Personal correspondence, 2018.

430 Fiedler, J. W., Brodie, K. L., McNinch, J. E., and Guza, R. T.: Observations of runup and energy flux on a low-slope beach with high-energy, long-period ocean swell, Geophys. Res. Letters, 42, 9933-9941, 2015.

Fielder, J. W., Smit, P. B., Brodie, K. L., McNinch, J. E., and Guza, R. T.: Numerical modeling of wave runup on steep and mildly sloping natural beaches, Coastal Eng., 131, 106-113, 2018.

García-Medina, G., Özkan-Haller, H. T., Holman, R. A., and Ruggiero, P.: Large runup controls on a gently sloping dissipative beach, J.

Geophys. Res.: Oceans, 122, 5998-6010, 2017.

García-Medina, G., Özkan-Haller, H. T., Ruggiero, P., Holman, R. A., and Nicolini, T.: Analysis and catalogue of sneaker waves in the US Pacific Northwest between 2005 and 2017, Nat. Haz., 94, 583-603, 2018.

Hedges, T. S., and Mase, H.: Modified Hunt's Equation Incorporating Wave Setup, J. Waterway, Port, Coastal, and Ocean Eng., 130, 109-113, 2004.

440 Holman, R. A., and Bowen, A. J.: Longshore structure of infragravity wave motions, J. Geophys. Res., 89, 6446-6452, 1984.

Holman, R. A.,: Extreme value statistics for wave run-up on a natural beach, Coastal, Eng., 9, 527-544, 1986.

Hughes S. A.: Estimation of wave run-up on smooth, impermeable slopes using the wave momentum flux parameter, Coastal Eng., 51, 1085-1104, 2004.

Hunt, I. A.: Design of Seawalls and Breakwaters, J. Waterways and Harbors Div., 85, 123-152, 1959. 
https://doi.org/10.5194/nhess-2020-425

Preprint. Discussion started: 26 January 2021

(C) Author(s) 2021. CC BY 4.0 License.

Hwang, P. A., Ocampo-Torres, F. J., and García-Nava, H.: Wind sea and swell separation of 1D wave spectrum by a spectrum integration method, J. Atmos. Ocean Technol., 29, 116-128, 2011.

Jensen, T. M.: Personal correspondence, 2016.

List, J. H.: A model for the generation of two-dimensional surfbeat, J. Geophys. Res., 97, 5623-5635, 1992.

Longuet-Higgins, M. S., and Stewart, R. W.: Radiation stress and mass transport in gravity waves, with applications to 'surf beats,' J. Fluid Mech., 13, 481-504, 1962.

Longuet-Higgins, M. S., and Stewart, R. W.: Radiation stress in water waves; a physical discussion, with applications, Deep-Sea Res., 11, $529-562,1964$

Mase, H.: Random Wave Runup Height on Gentle Slope, J. Waterway, Port, Coastal, and Ocean, Eng., 115, 649-661, 1989.

Monserrat, S., Vilibić, I., and Rabinovich, A. B.: Meteotsunamis: atmospherically induced destructive ocean waves in the tsunami frequency band, Nat. Hazards Earth Sys. Sci., 6, 1035-1051, 2006.

Monyta, L., and Lynett, P.: Tsunami versus Infragravity Surge: Comparison of the Physical Character of Extreme Runup, Geophys. Res. Letters, 45, 12982-12990, 2018.

Munk, W. H.: Surf Beats, Trans. AGU, 30-6, 849-854, 1949

National Oceanic and Atmospheric Administration's (NOAA) National Data Buoy Center: https://www.ndbc.noaa.gov, last access: 16 October 2020(a).

National Oceanic and Atmospheric Administration (NOAA) Tides and Currents: https://tidesandcurrents.noaa.gov, last access: 16 October 2020(b).

Olabarrieta M., Valle-Levinson, A., Martinez, C. J., Pattiaratchi, C., and Shi, L.: Meteotsunami in the northeastern Gulf of Mexico and their possible link to El Niño Southern Oscillation, Nat. Haz., 88, 1325, 2017.

465 Roeber, V., and Bricker, J. D.: Destructive tsunami-like wave generated by surf beat over a coral reef during Typhoon Haiyan, Nat. Comm., $6,7854,2015$.

Ruggiero, P., Komar, P. D., McDougal, W. G., Marra, J. J., Beach, R. A.: Wave Runup, Extreme Water Levels and the Erosion of Properties Backing Beaches, J. Coastal Res., 17, 407-419, 2001.

Ruggiero, P., Holman, R. A., and Beach, R. A.: Wave run-up on a high-energy dissipative beach, J. Geophys. Res., 109, C06025

Sheremet, A., Staples, T., Ardhuin, F., Suanez, S., Fichaut, B.: Observations of large infragravity wave runup at Banneg Island, France, Geophys. Res. Lett., 41, 976-982, 2014.

Sheremet, A., Gravois, U., and Shrira, V.: Observations of meteotsunami on the Louisiana shelf: a lone soliton with soliton pack, Nat Hazards, 84, 471-492, 2016.

Smit, P. B., Janssen, T. T., Herbers, T. H. C., Taira, T., and Romanowicz, B. A.: Infragravity wave radiation across the shelf break, Geophys. Res. Oceans, 123, 4483-4490, 2018.

Stockdon, H. F., Holman, R. A., Howd, P. A., and Sallenger, A. H.: Empirical parameterization of setup, swash, and runup, Coastal Eng., 53, 573-588, 2006.

Symonds, G., Huntley, D. A., and Bowen, A. J.: Two dimensional surfbeat: Long wave generation by a time varying breakpoint, J. Geophys. Res., 87, 492-498, 1982.

Tillotson, K., and Komar, P. D.: The Wave Climate of The Pacific Northwest (Oregon and Washington): A Comparison of Data Sources, J. Coastal Res., 13, 440-452, 1997.

Tucker, M. J.: Surf beats: waves of 1 to 5 min. period, Proc. R. Soc. Lond. A Math. Phys. Sci., 202-1071, 565-573, 1950 
https://doi.org/10.5194/nhess-2020-425

Preprint. Discussion started: 26 January 2021

(C) Author(s) 2021. CC BY 4.0 License.

(c) (1)

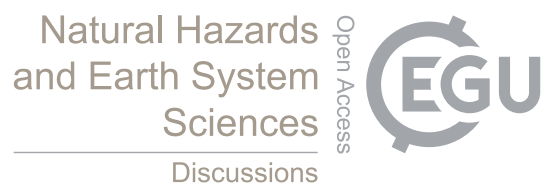

van der Meer, J. W., and Stam, C. M.: Wave runup on smooth and rock slopes of coastal structures, J. Waterway, Port, Coastal, and Ocean,

Eng., 118, 534-550, 1992.

van Dongeren, A., Battjes, J., Janssen, T., van Noorloos, J., Steenhauer, K., Steenbergen, G., and Reniers, A.: Shoaling and shoreline dissipation of low-frequency waves, J. Geophys. Res., 112, C02011, 2007.

Wilson, B. W.: Graphical approach to the forecasting of waves in moving fetches, Beach Erosion Board, U.S. Army Corps of Eng., Tech.

Memo. No. 73, 1955.

YouTube: https://youtu.be/JMYLvSsWR_g, last access: 5 October 2020(a).

490 YouTube: https://youtu.be/RPypT9dOvSY, last access: 5 October 2020(b).

YouTube: https://youtu.be/F0a_DDzEk-c, last access: 5 October 2020(c).

YouTube: https://youtu.be/HSCCe1y6-b8, last access: 5 October 2020(d).

YouTube: https://youtu.be/S6GJI6i6c1k, last access: 5 October 2020(e).

YouTube: https://youtu.be/IGSGNpfRFqQ, last access: 16 October 2020(f). 